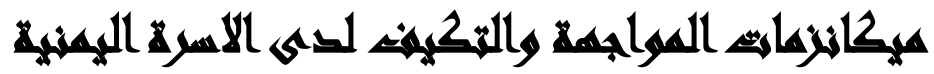

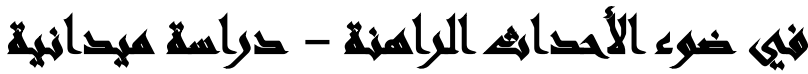

رغد زين العابدين محمد يوسف(')- أحمد مصطفى العتيق(')

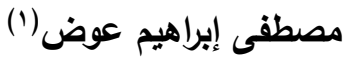

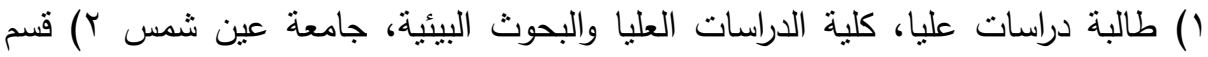

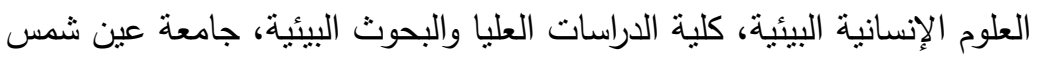

\section{المهتخلي}

بناء برامج عديدة ومتتوعة لمواجهة الظروف الصعبة التى هدفت الدراسة لتحديد

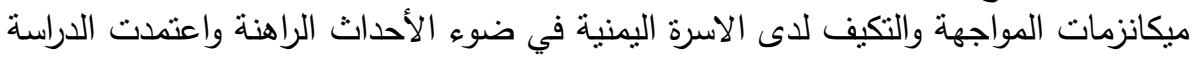

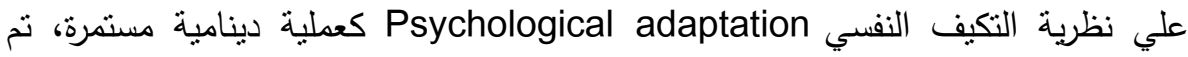
إجراء هذه الدراسة على مجموعة مكونة من (140) اسرة يمنية كما إستخدم الباحثون المنهج

$$
\text { وكانت أهم نتائج الدراسة ما التيلي ألئي: }
$$

توجد فروق جزئية عند مسنوى معنوية (0. ، • •) في العوامل الخمسة الكبرى للثخصية

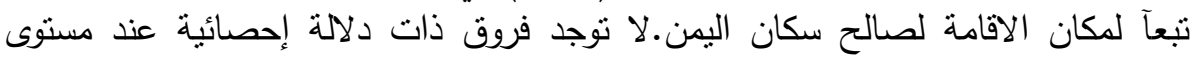

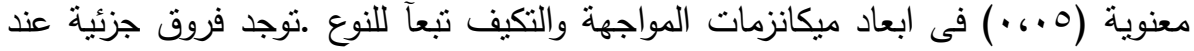

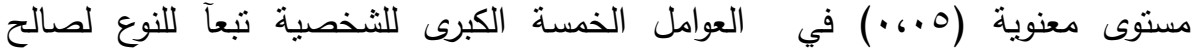
الانآث.توجد فروق جزئية فى العلاقة بين ميكانزمات المواجهة والتهية التكيف تبقآ لمتغير مكان

الاقامة لصالح يمنيون خارج اليمن في عينة الدراسة.

أوضحت هذه الدراسة ضرورة التركيز علي استراتيجية الوقاية من الاضرابات النفسية

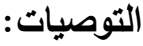

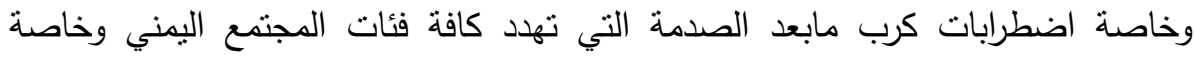

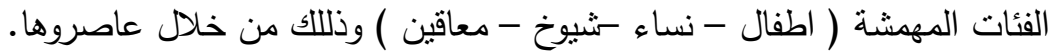

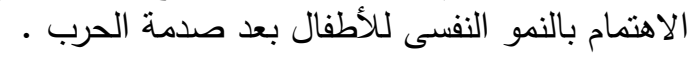

$$
\begin{aligned}
& \text { المجلد الخمسون، العدد العاثر الجزء الأول، أكتوبر ابr.r. } \\
& \text { التزقيم الدولي 0826-1110 1SSN } \\
& \text { الترقيم الدولي الموحد الإلكتروني 3178-2636 }
\end{aligned}
$$


1-تخصيص برامج إرشادية للافراد بعد الصدمة خاصة التوافق النفسى والاجتماعي.

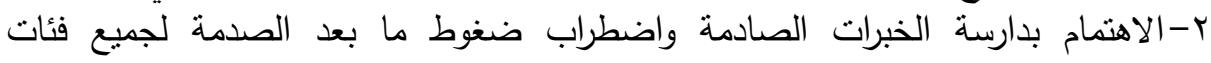
المجتمع. r-الاهتمام بالأوضاع الاقتصادية والسعى للتواصل مع المنظمات الدولية للحصول على

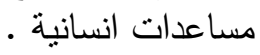
ع-ضرورة إنشاء مركز بحثي خاص باتئي الأيتام والتركيز على الإرشاد الجماعي والفردي والتزبوي

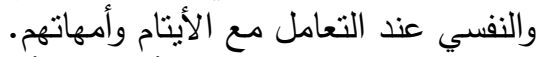
0-ضرورة تحديد احتباجات المرأة بشكل أساسى فئه في كل دولة حسب امكانياتهاتها سواء صحية

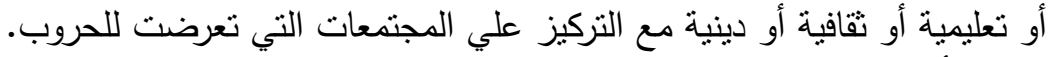

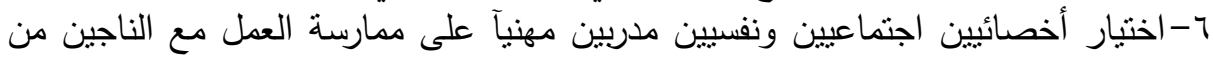

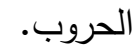

V- ضرورة التتسيق بين المنظمات الدولية ومساندة المجتمعات التي تعرضت أو مازالت تواجه الحروب.

^-حث المجتمع الدولى للضغط على اطراف الصراع للضرورة الملحة لوقف الحرب بشكل

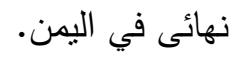
9-ضرورة التعاون الدولي لاعادة البنى التحتية للمجتمعات التي تعرضت لادمار الحروب.

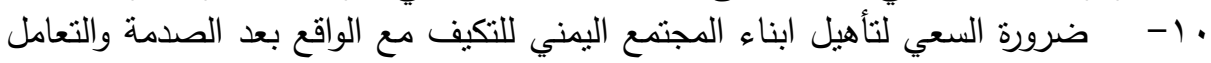
مع جميع الاسر والافراد المنضرريين. الهين.

\section{هنتصة}

الحروب والصراعات المسلحة ليست وليدة اليوم، فقد عرفت المجتمعات البشرية منذ همهة نشأتها حروب ونزاعات خلفت معاناة ومآسي في حق الانسانية وهذا عائدا إلى غريزة الإنسان في السيطرة والتملك واستخدام القوة دون الاستتاد إلى أية قواعد وضوابط تحكية تحكمه سواء كانت قانونية أو أخلاقية الإِ أنه منذ الحرب العالمية الثانية انخفض العض العدد الفعلي للنزاعات وعدد المدنيين المتأثرين بالنزاع إلى حد كبير ، ومع ذلك فإن الادراك العام هو أن أن

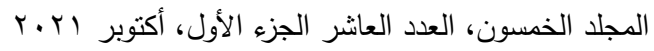

$$
\begin{aligned}
& \text { التزقيم الدولي 0826-1110 1SSN } \\
& \text { التزقيم الدولي الموحد الإلكتروني 3178-2636 }
\end{aligned}
$$


مجلة العلوم البيئية

كلية الدراسات العليا والبحوث البيئية - جامعة عين شمس الئية

رغد زين العابدين محمد يوسف وآخرون

العالم يعيش وسط نزاعات وأزمات مدمرة وغير مسبوقة، وأصبحت هذه النزاعات في أنحاء متعددة من العالم أكثر طولا تدمر الحياة المدنية

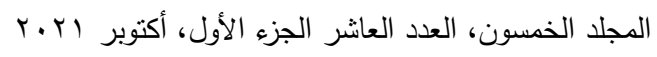

الترقيم الدولي 0826- ISSN 1110

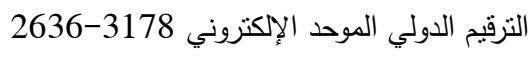


وتأتي اليمن كإحدى دول المنطقة التي طال فيها أمد الحرب، فقد دخلت حرب اليمن المدمرة عامها السابع محدثة الكثير من الانعكاسات والاثار السلبية في المجتمع اليمني، حيث أثنارت دراسة علمية أجراها المرصد اليمني لحقوق الانسان عام (2017)م 3 ) ) إلي الي ان الحرب في اليمن خلفت خسائر مروعة فقد أطاحت بمنجزات خمسة عقود من التنمية لتتقل اليمن إلى الوراء خمسين عاما، وأصبحت اليمن غارقة في أزمة إنسانية، فالمدنيون في

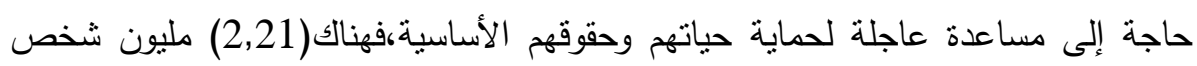

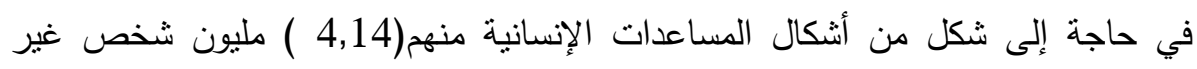

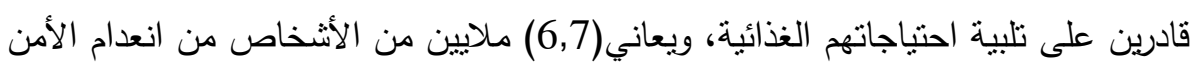

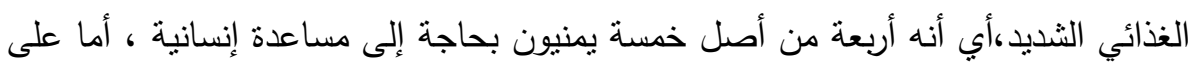

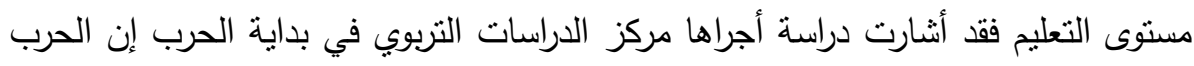

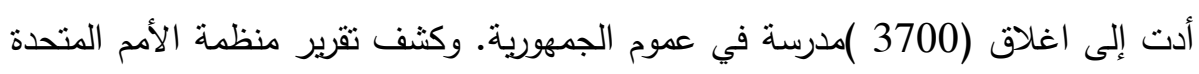
للطفولة "يونيسيف"2019 بشأن التعليم في اليمن أن نحو (500 ) ألف طفل عندي يمني انقطعوا

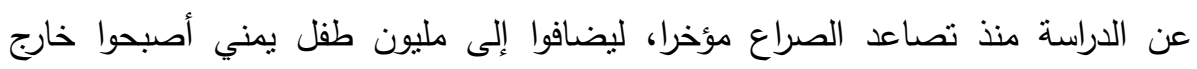
المنظومة التعليمية منذ بدء الحرب بالبلاد عام 2015م، وأن المنظومة التعليمية في اليمن لئن تأثرت بشكل كبير بسبب عددة عوامل منها التوقف عن صرف رواتب الكوادر التعليمية

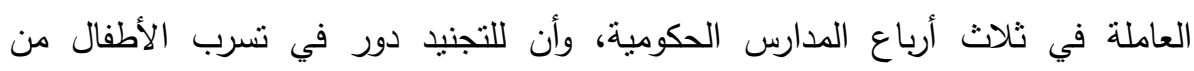

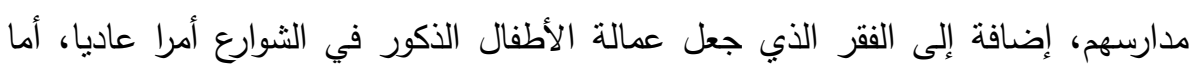

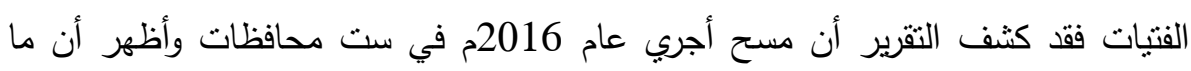

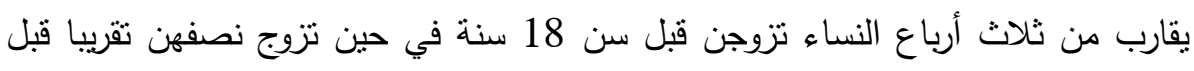

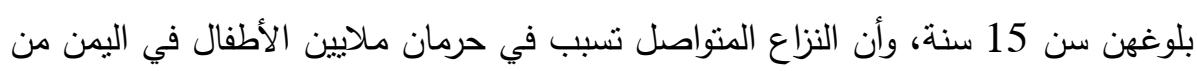


حقهم في التعليم، والصحة وأن العنف والنزوح والهجمات التي تتعرض لها المدارس يحول دون وصول العديد من الأطفال إلى المدارس.

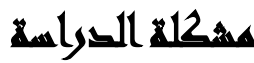

وأثنار مركز صنعاء للدراسات الاستراتجية (Y V V الي أن الحرب في اليمن تركت

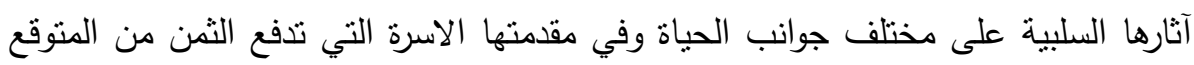

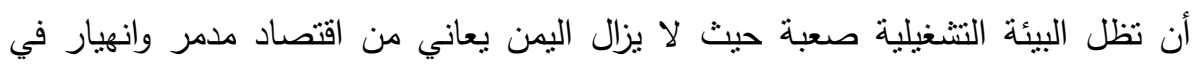
المؤسسات والخدمات العامة، والتي تفاقمت بسبب المخاوف الأمنية وعدم الاستقرار السياسي. مع ظهور جبهات للقتال عبر عددة محافظات، يستمر النزوح المتكرر والمتواصل والمتعلق بالنزاع إلى جانب انتهاكات القانون الإنساني الدولي وحقوق الإنسان. كما اثشار

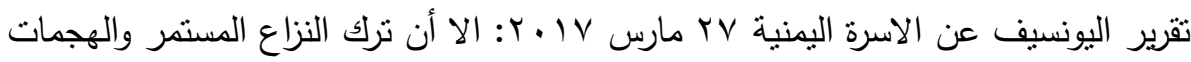

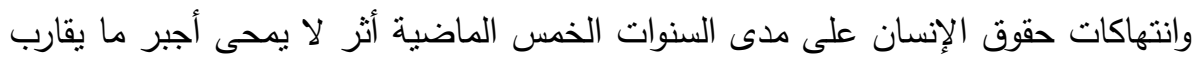

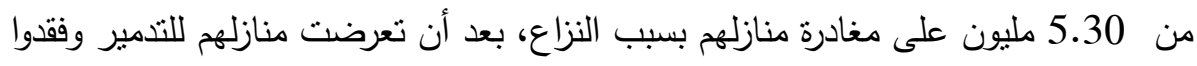

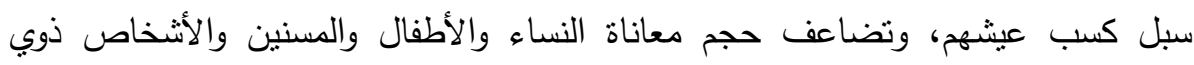
الإعاقة بسبب استمرار القتال وتدهور الاقتصاد وتوقف الخدمات العامة منل النظام القضائي ومراكز التسجيل والمستشفيات والمدارس وغيرها.

\section{أسئلة السراسما}

السوال الرئيسي للاراسة:

- ما ميكانزمات المواجهة والتكيف لاى الاسرة اليمنية في ضوء الأحداث

الراهنة؟

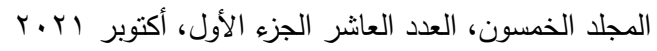

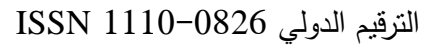

$$
\begin{aligned}
& \text { التزقيم الدولي الموحد الإلكتروني 3178-2636 }
\end{aligned}
$$


1 ـ ما ميكانزمات المواجهة والتكيف لدى يمنيون خارج اليمن؟

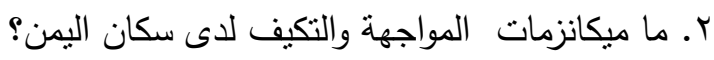

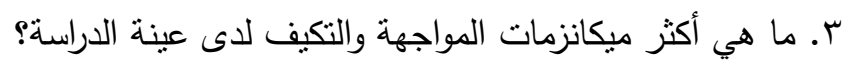

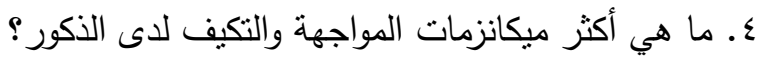

0. ما هي أكثر ميكانزمات المواجهة والتكيف لدى الإناث؟

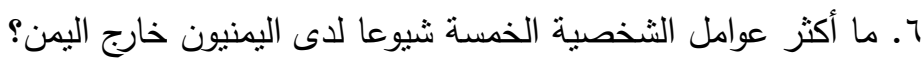

V. ما أكثر عوامل الثخصية الخمسة شيوعا لدى سكان اليمن؟

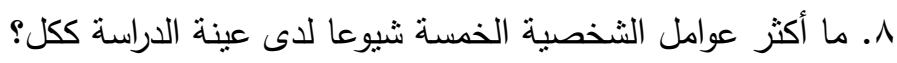

9. ما أكثر عوامل الثخصية الخمسة شيوعا لدى الذكور؟

\section{هزوضر الهمبه}

- توجد فروق ذات دلالة إحصائية عند مستوى دلالة (0.05 = م) في العوامل الخمسة الكبرى للشخصية بين يمنيون خارج اليمن وسكان اليمن.

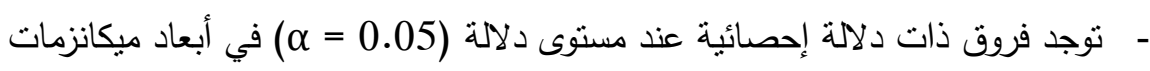
المواجهة والتكيف بين الذكور والإناث.

- توجد فروق ذات دلالة إحصائية عند مستوى دلالة (0.05 = م) في العوامل الخمسة الكبرى للشخصية بين الذكور والاناث.

- - نوجد فروق ذات دلالة إحصائية عند مستوى دلالة (0.05 = م) في أبعاد ميكانزمات المواجهة والتكيف بين يمنيون خارج اليمن وسكان اليمن. 


\section{أهماهثم الكراسة}

$$
\text { تتبلور أهداف الدراسة فيما يلي: }
$$

- تحديد ميكانزمات المواجهة والتكيف لدى الاسرة اليمنية في ضوء الأحداث الراهنة.

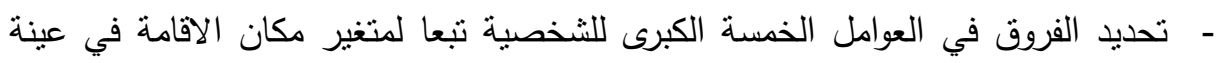

- - تحيديد الفروق في مكانزمات المواجهة والتكيف تبعا لمتغير النوع في عينة الدراسة. - تحيديد الفروق في العوامل الخمسة الكبرى تبعا لمتغير النوع في عينة الدراسة.

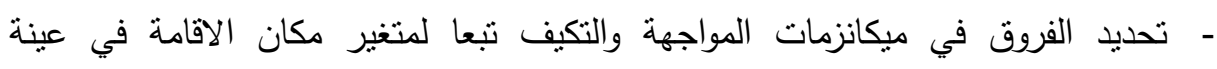
الدراسة.

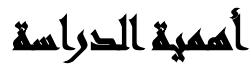

تبرز أهمية الدراسة من أهمية موضوعها ميكانزمات المواجهة والتكيف لدى الاسرة

$$
\text { اليمنية في ضوء الأحداث الراهنة. }
$$

يتتاول موضوعا جديدا حيث طالت فترة الحرب التي تعيشها اليمن مما نولا عنها انعكاسات وآثار سلبية في العديد من فئات المجتمع الحين ومستقبلاً.

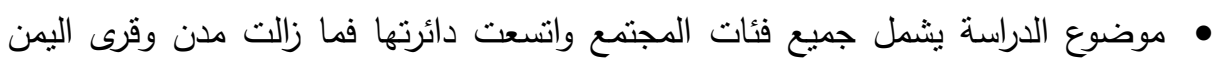
تسقط في هاوية الصراع واتساع دائرة المتضررين وتتمل الاطفال والنساء والثباب والمسنين. • تقليص سبل التكيف بشكل حاد علي المجتمع اليمنى حيث يعيش الناس أكبر ازمة إنسانية

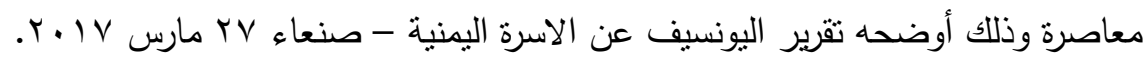

$$
\begin{aligned}
& \text { المجلد الخمسون، العدد العاثر الجزء الأول، أكتوبر ابr.r. } \\
& \text { التزقيم الدولي 0826- ISSN 1110 } \\
& \text { الترقيم الدولي الموحد الإلكتروني 3178-2636-26 التربي }
\end{aligned}
$$


• التركيز علي اهمية وفاعلية وتأثثر الامن النفسي في بناء شخصية الفرد وتأثير الخبرات

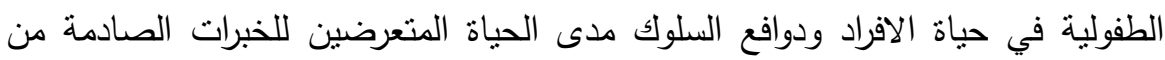

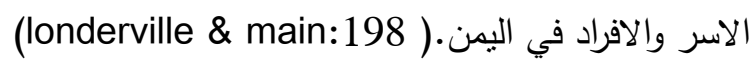

• تحديد وحصر إحتياجات الاسر والافراد الذين عاشوا الخبرة الصادمة للحرب في اليمن

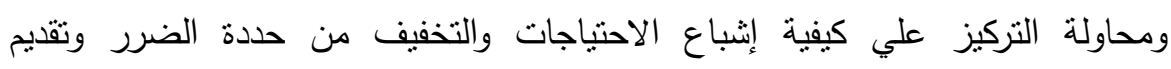

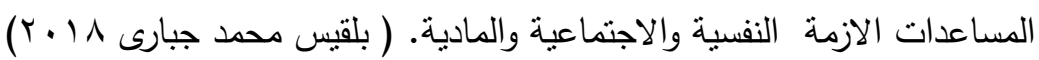

النظريات المرتبطة بمتغيرات الاراسة: واقع اليمن وميكانزمات المواجهة والتكيف في زمن ولناءنه الحرب:

وقد كثف تقرير مدير مؤسسة تمكين المراة اليمنية د/ زعفران زايد ان معاناة النساء في الحرب اليمنية لا تقتصر على ظروف النزوح ومشاعر الخوف من عمليات القصف، بل تزداد

قساوة في ظل انقطاع الخدمات العامة، مما يدعوهن للقيام بمهمات شاقة في ظل انشغال الرجال بالحرب وبالبحث عن فرص لإعالة أسرهن.

كثير من النساء اليمنيات خصوصا الحوامل منهن يرفضن الذهاب الى المستشفيات الدهن

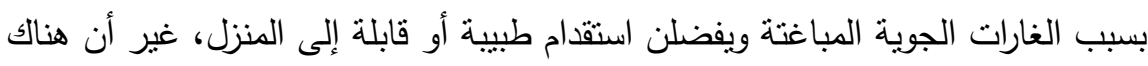

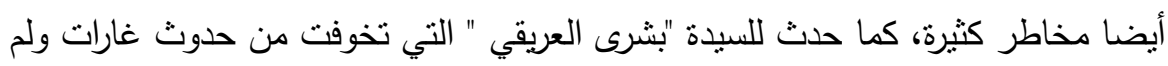
تذهب للولادة بالمستشفى. وتقول" بشرى" الموت في منزلي أهون من الموت في الطريق. لكني

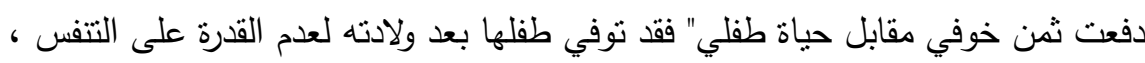
حيث لم يكن بالبيت جهاز اكسجين، كما في المسنتفى دئى

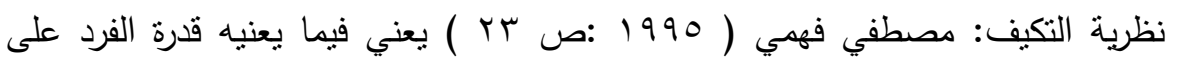

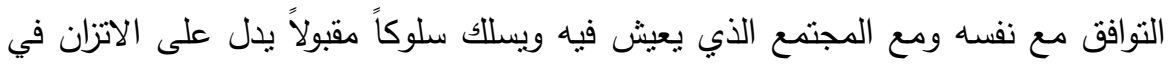
مختلف المجالات، وتحت ثأثثر جميع الظروف وهو عملية ديناميكية مستمرة نتمل لتعل

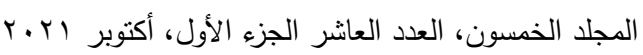

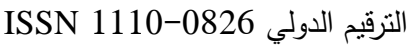

$$
\begin{aligned}
& \text { الترقيم الدولي الموحد الإكتروني 3178-2636-26 }
\end{aligned}
$$


اكتساب وتبني اساليب من السلوك تكون ملائمة للبيئة وتغيراتها، وان مفهوم التكيف أصلا هو مفهوم بيولوجي، كان حجر الزاوية في نظرية داروين عن الانتخاب الطبيعي وبقاء الأصلح فالحيوانات التي استطاعت التلاؤم مع بيئتها الطبيعية أستمرت في البقاء كالحرباء التي تغير لونها ليتتاسب مع البيئة الطبيعية، وهجرة أسماك السلمون والإنسان بعمل باستمرار على التكيف مع بيئته الطبيعة عن طريق ارتداء اللباس المناسب وشكل لفئه البناء

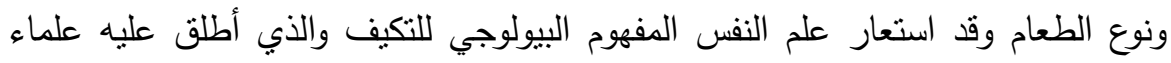
البيولوجيا مصطلح تلاؤم أو توافق اذ أن الإنسان يتلاءم مع بيئته النفسية والاجتماعية النئية

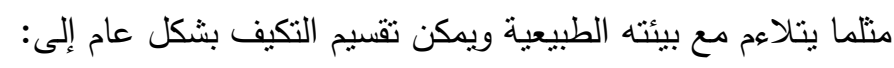

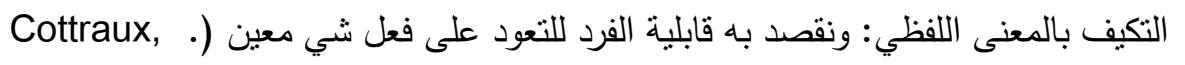
.) (1990, p 204

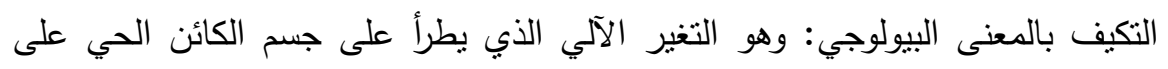

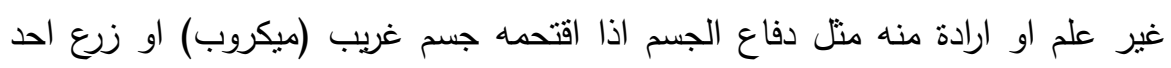

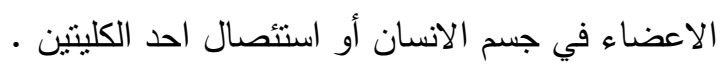

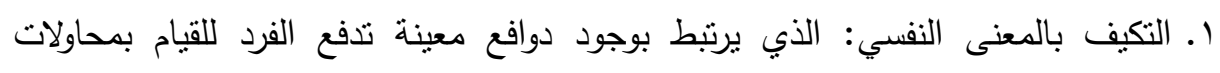

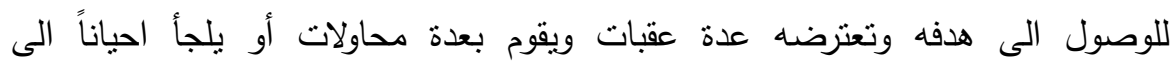
الانسحاب او الهروب من الموقف، وفي هذه الحالة تبقى الصعوبة قائمة فهو عملية لهدية يمارسها الفرد شعوريا أو لا شعوريا تهدف إلى تغيير سلوكه ليصبح أكثر توافقا مع بيئته

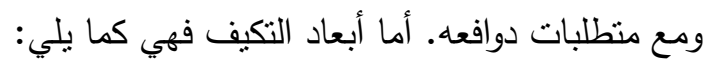

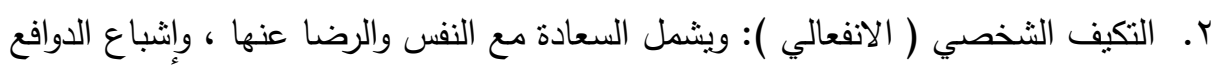

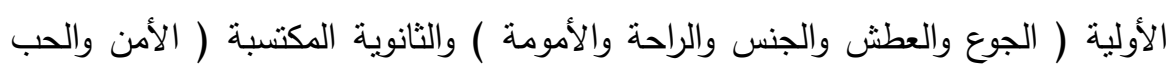

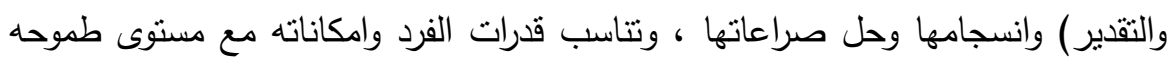

$$
\begin{aligned}
& \text { المجلد الخمسون، العدد العاثر الجزء الأول، أكتوبر ابr.r. }
\end{aligned}
$$

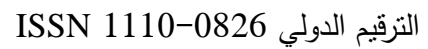

$$
\begin{aligned}
& \text { الترقيم الدولي الموحد الإكتروني 3178-2636 }
\end{aligned}
$$


وأهدافه والتكيف الاجتماعي : يشمل السعادة مع الآخرين والالتزام بقوانين المجتمع وقيمه والتفاعل الاجتماعي السوي ، والعمل للخير والسعادة الزوجية ، والراحة المهنية.

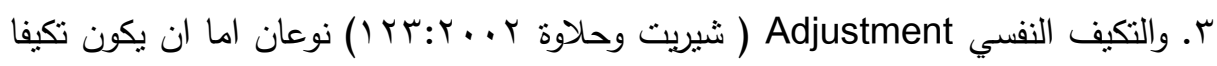
، حسنا او تكيفا سيئا

ع. فالتكيف الحسن: هو قدرة الفرد على اشباع حاجاته بطريقة مقبولة ، بحيث لا بصطدم

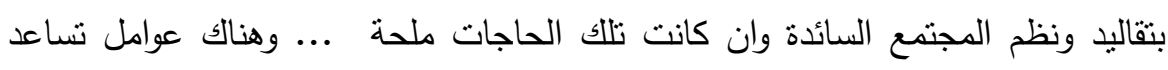

الفرد على التكيف الحسن منها: الفعان

$$
\text { • اثباع الحاجات الضرورية. }
$$

• • اكتساب الفرد العادات والمهارات السليمة التي تساعده على اثشباع حاجاته.

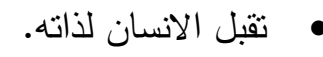
• • • • معرفة الانسان لنفسه.

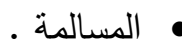

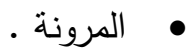

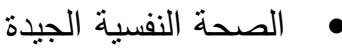
أما التكيف السيء: فهو عجز الفرد عن اشباع حاجاته بطريقة مرضية له وللآخرين وسبب

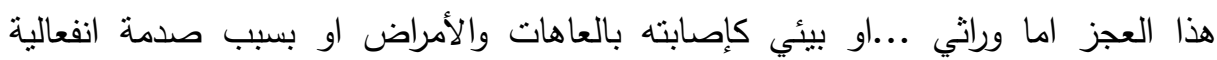
شديدة، وعندما يعجز عن اثنباع حاجاته يصيبه الثعور بالإحباط والفشل وهذا بدوره يسبب له القلق والتوتز لكن بطريقة غير شعورية وسوف يواجه هذا العجز بوسائل لا شعورية اوما

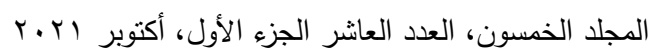

$$
\begin{aligned}
& \text { الترقيم الدولي 0826- ISSN 1110 } \\
& \text { التزقيم الدولي الموحد الإلكتروني 3178-2636 }
\end{aligned}
$$


الحيل الدفاعية Defense Mechanisms: ( طه 1999: 1 V9 ) ليتخلص من خلالها من

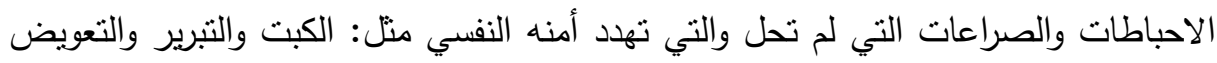

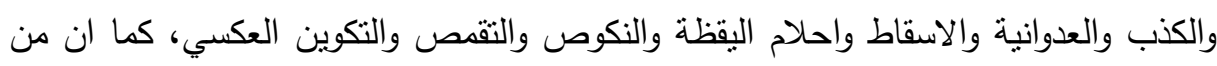

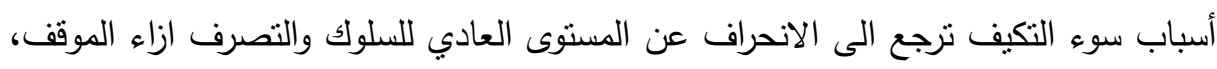

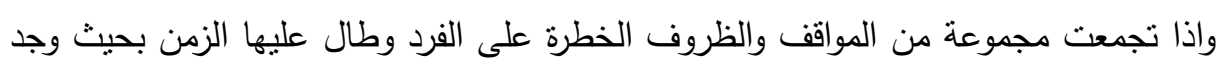
نفسه في مأزق يصعب الخلاص منه فحينئذ يهتز بناء شخصيته وتزداد فيها مشاعر القلق

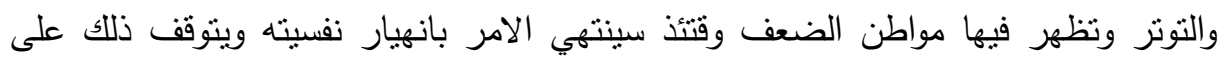
طبيعته الثخصية Personality ومقدرتها على التحمل وفيما لو كانت هذه الثخصية : أ- شخصية مريضة وليست شخصية سوية ب- شخصية قلقة وخائفة ج- شخصية غير مستقرة د- شخصية مختلقة للأعذار للتهرب من المسؤولية إذ ان شخصية الفرد هي جملة من الصفات الجسمية والعقلية والمزاجية والاجنماعية والخلقية التي يتسم بها شخصاً ما عن غيره .. يتأثر هذا النظام الى درجة كبيرة بسلامة الجهازين العصبي والغدي وخلوه من الصراعات النفسية الموصولة العنيفة الثعورية واللاشعورية ، كالصراع بين غرائز الفرد وضميره وبين نزواته وعاطفة احترامه لنفسه، وبين قدراته وطموحاته فضلا عن خلو شخصيته من العقد النفسية المتراكمة من مرحلة الطفولة (P37,2003,Sillamy Norbert)

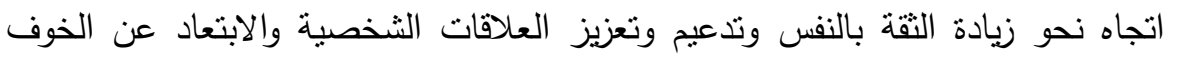

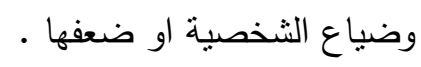$$
\text { الاتجاه نحو الصراحة والانفتاح مع الاخرين والابتعاد عن الانعزالية. }
$$

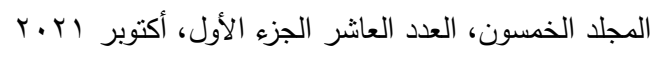

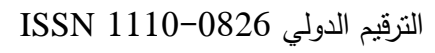

$$
\text { التزقيم الدولي الموحد الإلكتروني 3178-2636 الترولي }
$$




$$
\text { • الاتجاه نحو الاعتماد على النفس وانه قادر علي فعل اي شيء . }
$$

نستخلص من السابق التعريف الاجرائى للتكيف هو :- هو عملية دينامية مستمرة نتتاول

السلوك والبيئة والطبيعة الاجتماعية بالتغير والتعديل حتى يحدث التوازن بين الفرد والبيئة.

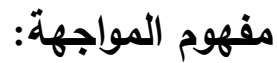

المواجهة : ظهر هذا المصطلح فى أواخر الستينات من القرن التاسع عشر عرفها لازاروس

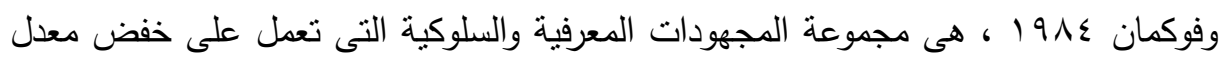

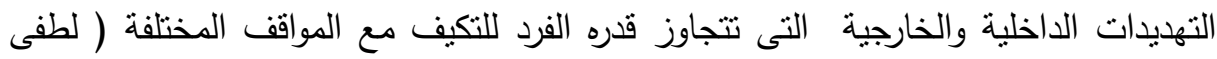

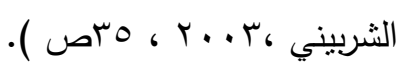
لغوياً - اصلها انجليزية ( Coping) وهى التسوية أو التعامل أى استجابات تكيفية للتغيرات النى تحدث فى البيئة المحيطة للفرد. التعريف الاجرائى للمواجهة: هى ذلك التعبير المستمر فى المجهودات المعرفية والسلوكية والانفعالية من أجل ادارة المطالب الداخلية والخارجية التى يقيمها الفرد بأنها ترهق أو تفوق

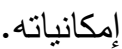

وجميع التعريفات إتققت أن اساليب المواجهة ، أنها تعبر عن مجهودات يقوم بها الفرد بهدف التحكم فى المشقة وتخفيض الضيق وتعديل الموقف الى الافضل وصولا الى المحافظة قدر الامكان على توازن الفرد الانفعالى وتكيفه النفسى والاجتماعى. لهئ.

\section{التوراسايت الماريهن}

ا. دراسـة (2010، Hart \& Gillath) بعـوان آثار الأمن النفسي وانعـام الأمن على

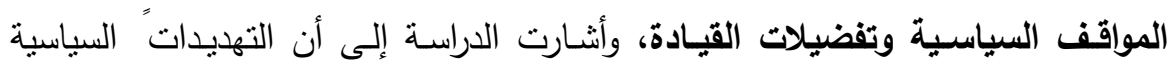

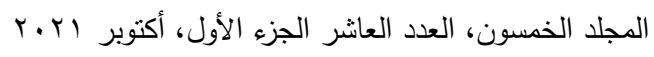

$$
\begin{aligned}
& \text { الترقيم الدولي 0826-0 } \\
& \text { الترقيم الدولي الموحد الإكتروني 3178-2636 }
\end{aligned}
$$


عن الأمن، تسبب الثعور بعدم الأمن، وتحفز الفرد لتبني قيم سياسية معينة والحد من

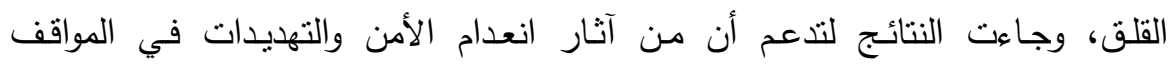

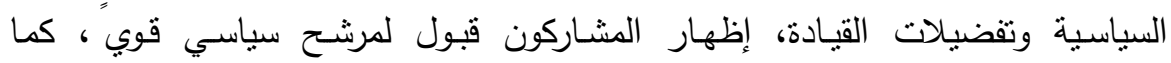

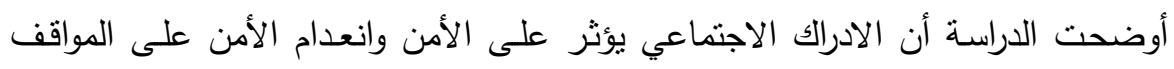
والسـوكيات.

r. دراسة Kuma , \& Kadhiravan 2012 والتي أثشارت إلى أن الضغوط تزداد نتيجة عوامل منتوعة منها زيادة الضغط، والتتافس، وقلة المصادر ، والدعم العائلي غير الكافي

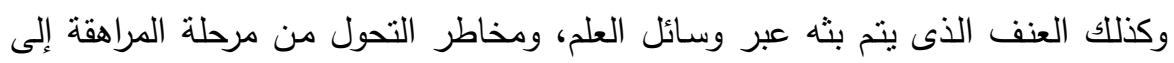
مرحلة الرشد، وأثـارت نتائج الدراسة إلى أن :التدريب على ولى استخدام مهارات المواجهة

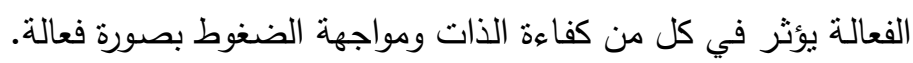
r. دراسـة 2012، Krageloh \& Christian وهدفت إلى الكثف عن عن المستوي الديني

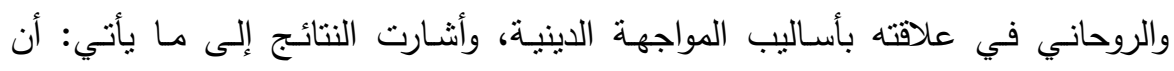
الأفراد ذوي المستوي الدينى والروحاني المنخفض يميلون إلى استخدام إستراتيجيات

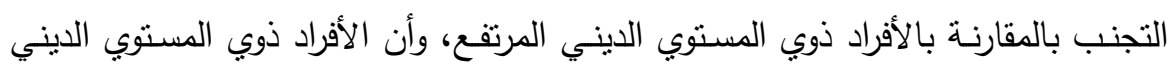
المرتفع يميلون إلى استخدام إستراتيجيات المواجهة المتمركزة حول المشكلة. ع. دراسـة Macneil \& Laura،2012 والتي توصلت إلى أن الطلاب الذين بيتخدمون أسـاليب التجنب لديهم ضغوط يوميـة مرتفعة كما أن لديهم اضطرابـات في الأكل

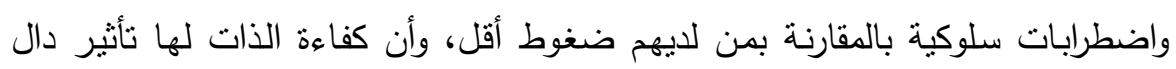
فى مواجهة الضغوط وأن من لديهم ثقة أقل بالنفس تزداد لديهم اضطرابـات الأكل والاضطرابات السلوكية.

$$
\begin{aligned}
& \text { المجلد الخمسون، العدد العانشر الجزء الأول، أكتوبر ابr.r } \\
& \text { التزقيم الدولي 0826- ISSN 1110 } \\
& \text { الترقيم الدولي الموحد الإكتروني 3178-2636 }
\end{aligned}
$$


0. دراسـة 2012، Zelviene \& Paulina التي هدفت إلى الكثف عن الرابطة بين

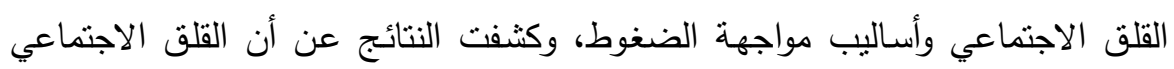

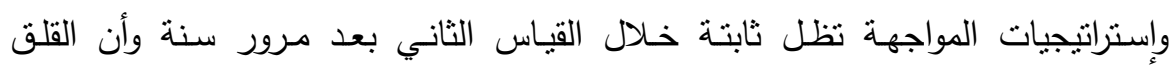
الاجتماعي له علاقة دالة مع العوامل المعرفية وإستراتيجيات المواجهة. 7. دراسـة 2012، Swanepoel \& Phile والتي هدفت إلى تحديد دور أساليب مواجهة الضغوط في العلاقة بين الصحة النفسية والاكتئاب، وأنشارت النتائج إلى أنه: لا توجد الند علاقة ارتباطية دالة بين أساليب المواجهة المتمركزة حول المشكلة المتمركزة حول الانفعال والاكتئاب- تلعب أساليب المواجهة المتمركزة حول المشكلة دورا بين الصحة الصنة النفسية والاكتئاب - تلعب أساليب المواجهة المتمركزة حول الانفعال دورا في العلاقة بين الصحة النفسية والاكتئاب- توجد علاقة ارتباطية سالبة بين الصحة النفسية والاكتئاب توجد علاقة ارتباطية إيجابية بين أساليب المواجهة والاكتئاب.

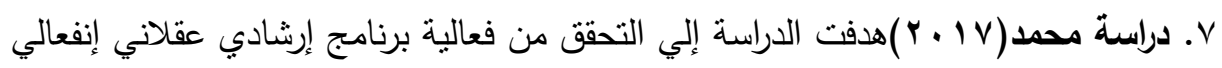

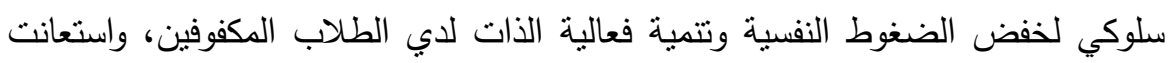

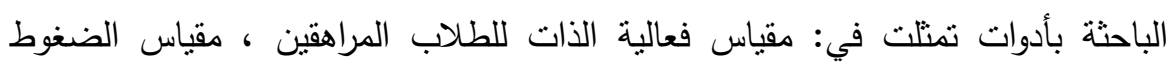

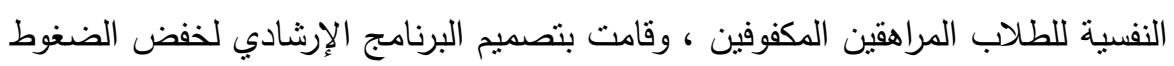

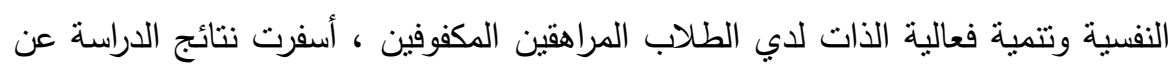
وجود فروق ذات دلالة إحصائية بين متوسطات درجات أفراد المجموعنين التجريبية والضابطة علي مقياسي الضغوط النفسية وفعالية الذات في القياس البعدي لصالح المجموعة التجريبية، مما يشير إلي فعالية البرنامج الإرشادي العقلاني الإنفعالي السلوكي في خفض الضغوط النفسية وتتمية فعالية الذات لدي الطلاب المكفوفين.

$$
\begin{aligned}
& \text { المجلد الخمسون، العدد العاثر الجزء الأول، أكتوبر ابr.r. } \\
& \text { التزقيم الدولي 0826- ISSN 1110 } \\
& \text { الترقيم الدولي الموحد الإكتروني 3178-2636 }
\end{aligned}
$$




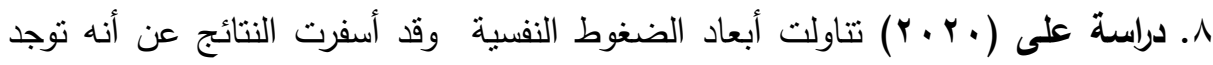

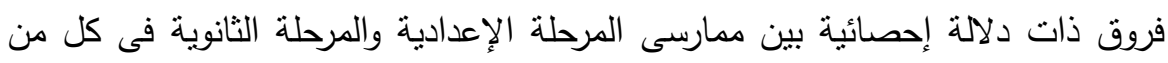

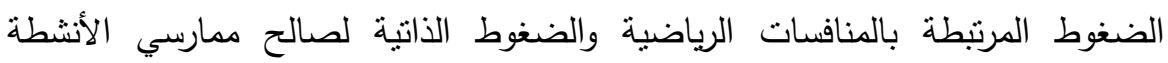
الخارجية من كل طلاب المرحلة الثانوية، كما أسفرت النتائج عن عدم وجود فروق بين ممارسى الأنشطة الرياضية الخارجية بالمعاهد الأزهرية وفقاً للمرحله الدراسية والضغوط عندانه الأسرية والضغوط المرتبطة بالمنافسات الرياضية والضغوط المرتبطة بإدارة المعهد وتتظيم

الوقت والضغوط الذاتية الشخصية.

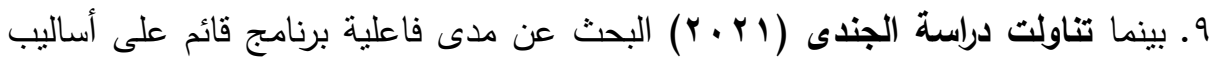
مواجهة الضغوط النفسية لرفع الكفاءة المهنية لمعلمات في مرحلة الطفولة المبكرة في خفض الضغوط النفسية لديهن عن طريق نتمية أساليب مواجهة الضغوط النفسية والمساهمة من خلالها في رفع الكفاءة المهنية لديهن ويهدف البرنامج الحالي الي التعرف على اساليب مواجهة الضغوط النفسية شيوعا وانتشارا لديهن.

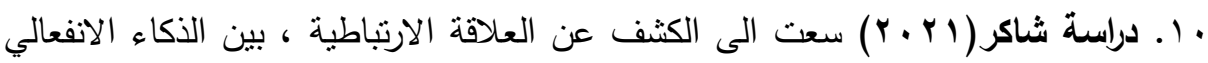
واستراتيجيات التكيف الإيجابية مع الضغوط النفسية ، لدى طلاب الجامعة. ، وكذلك كثفت عن الفروق في الذكاء الانفعالي خاصة في ضوء متغيرات كالنوع، التخصص مع وجود مجموعة من الفروق في استراتيجيات التكيف الإيجابية مع الضغوط النفسية.

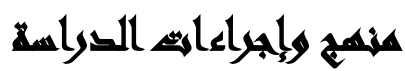

منهج الاراسة: في سبيل تحقيق هدف الدراسة واختبار فروضها، اعتمد الباحثون في هذه الدراسة على المنهج الوصفي التحليلي وأسلوب الدراسة الميدانية لجمع المعلومات والبيانات اللازمة لإتمام الدراسة.

$$
\begin{aligned}
& \text { المجلد الخمسون، العدد العاثر الجزء الأول، أكتوبر اب.r.T }
\end{aligned}
$$

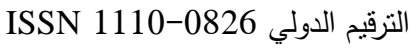

$$
\begin{aligned}
& \text { الترقيم الدولي الموحد الإلكتروني 3178-2636-26 التروب }
\end{aligned}
$$


أما مصدر البيانات فقد تم الحصول عليها من مصدرين هما:

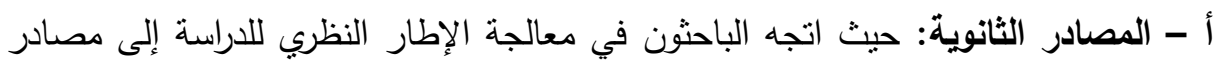

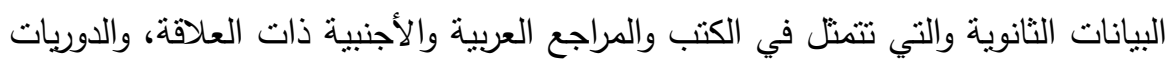
والمقالات والتقارير، والأبحاث والدراسات السابقة التي تتاولت موضوع الدارسة، والبات والبحث

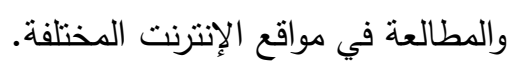

ب - المصادر الأولية: تتمثل في جمع البيانات الأولية ميدانياً، وذللك من خلال استخدام

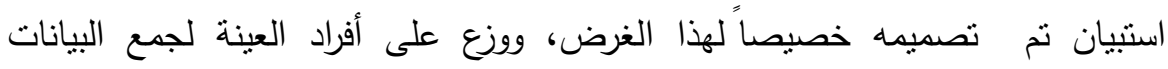$$
\text { المطلوبة. }
$$ \\ أهداف الدراسة: - مانه}

- - تحديد ميكانزمات المواجهة والتكيف لدى الاسرة اليمنية في ضوء الأحداث الراهنة. - تحديد الفروق في العوامل الخمسة الكبرى للشخصية تبعا لـتغير مكان الاقامة في عينة

- - تحيديد الفروق في مكانزمات المواجهة والتكيف تبعا لمتغير النوع في عينة الدراسة. - تحيديد الفروق في العوامل الخمسة الكبرى تبعا لمتغير النوع في عينة الدراسة.

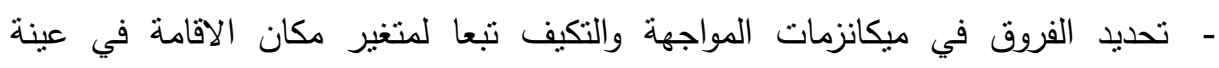

ميدان الدراسة: نم إجراء هذه الدراسة على مجموعة مكون من $(140)$ فرد 70 شخص من سكان اليمن، ومجموعة مكونة من 70 شخص من يمنيون خارج اليمن في الفترة الزمنية

$$
\begin{aligned}
& \text { المجلد الخمسون، العدد العاثر الجزء الأول، أكتوبر ابr.r. } \\
& \text { الترقيم الدولي 0826- ISSN 1110 } \\
& \text { الترقيم الدولي الموحد الإلكتروني 3178-2636-26 }
\end{aligned}
$$


أ - العينة الاستطلاعية: أجريت هذه الدراسة الاسنطلاعبة على عينة مكونة من (40) فرد من أجل الإجابة على استبيان نم إرجاعه كاملا، للتأكد من صدق وتثات المقاييس المستخدمة في البحث.

ب - أداة القياس: اعتمد الباحثون في الدراسة الحالية على مقياس ميكانزمات المواجهة والتكيف وهو من إعداد الباحثون، ومقياس العوامل الخمسة الكبرى للشخصية. ج -الخصائص السيكومترية لأداة القياس: للتأكد من أداة الدراسة المستخدمة تسنطيع أن تقيس ما وضعت من أجله لتقيسه، ويجب قياس الخصائص السيكومترية لهذه الأداة وهذه لأهن الخصائص تتمثل في الصدق والثبات وسنتطرق إلى كيفية حساب كل خاصية من هاتين الخاصينتين.

هـ - العينة الفعلية: بعد التحقق من صدق أداة القياس وثباتها، وزعت الاستمارات على أفراد عينة الدراسة، حيث تكونت عينة الدراسة من مجموعتين، مجموعة سكان اليمن وعددها

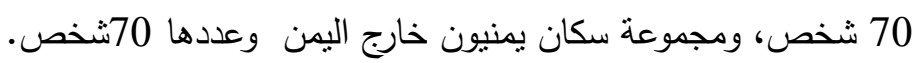

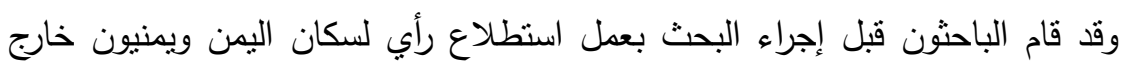
اليمن للتعرف علي أهم المشكلات التي نواجههم. أداوت الدراسة: قام الباحثون باستخدام أداتين للإراسة: 1 - مقياس ميكانزمات المواجهة والتكيف ، وهو من إعداد الباحثة.

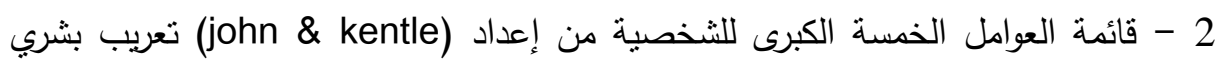
إسماعيل أحمد.

الأداة الأولي: مقياس ميكانزمات المواجهة وإلتكيف: قامت الباحثة بصياغة أولية لعبارات لمقياس ميكانزمات المواجهة والتكيف النطلاقا من موضوع الدراسة وأهدافها وتساؤلاتها

$$
\begin{aligned}
& \text { المجلد الخمسون، العدد العاثر الجزء الأول، أكتوبر ابr.r. }
\end{aligned}
$$

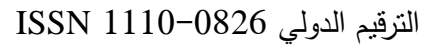

$$
\begin{aligned}
& \text { الترقيم الدولي الموحد الإلكتروني 3178-2636-26 التربي }
\end{aligned}
$$


وذلك بعد القراءة المتأنية والاطلاع على الأدبيات والدراسات السابقة المتعلقة بمشكلة الدراسة وخبرة الباحثة العملية. ا ـ وصف قياس مكيانزمات المواجهة والتكيف: قام الباحثون بتحديد الابعاد التي نتشل عليها

$$
\text { المقاس والتي تمثلت في أربعة أبعاد وهي: التئي }
$$

• أسلوب التعايش مع الضغوط الحياتية المتمركزة علي حل المشكلة. •أسلوب التعايش مع الضغوط الحياتية المتمركزة علي التنفيس الانفعالى. • أسلوب التعايش مع الضغوط الحياتية المتمركزة علي المساندة الاجتماعية. • أسلوب التعايش مع الضغوط الحياتية التجنبية. ثم صياغة كل بعد ويشمل • ا 1 عبارات لكل بعد.

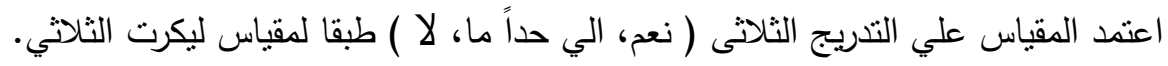
ولقد نم احتساب مستوي الاهمية وفقا للمعادلة التالية:

$$
\text { مستوي الاهمية = ( الحد الاعلى للاجابة - الحد الادنى للاجابة) ) الحد الاعلي للاجابة. }
$$

أولا: صدق مقياس ميكانزمات المواجهة والتنكييف:

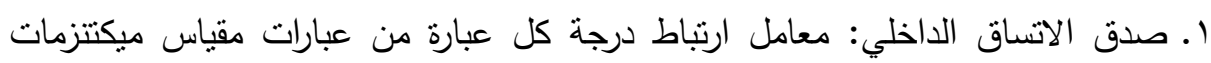

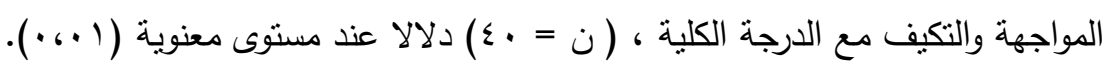

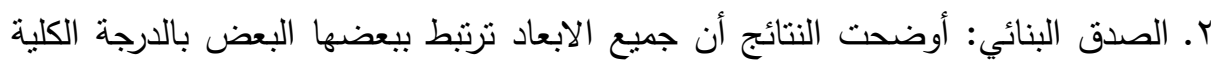

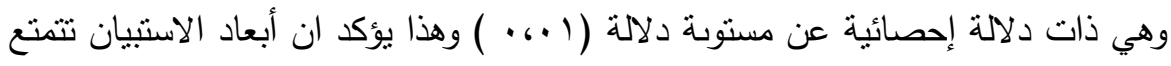

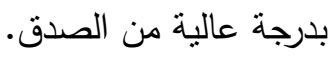

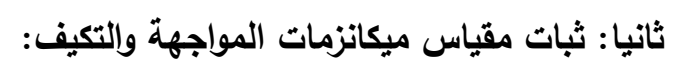
ا ـ طريقة التجزئة النصفية: أثنتت النتائج أن معامل الثبات الكلى مقياس ميكانزمات النيات المواجهة والتكيف ( T9V \% \% ) أي انها تتمتع بدرجة عالية من الثبات.

$$
\begin{aligned}
& \text { المجلد الخمسون، العدد العاثر الجزء الأول، أكتوبر ابr.r. }
\end{aligned}
$$

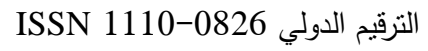

$$
\begin{aligned}
& \text { الترقيم الدولي الموحد الإلكتروني 3178-2636-26 }
\end{aligned}
$$


r. معامل ألفاكرنباخ: وهي طريقة تعتمد على حساب تباينات الفقرات وتباين الاختبار وعلى

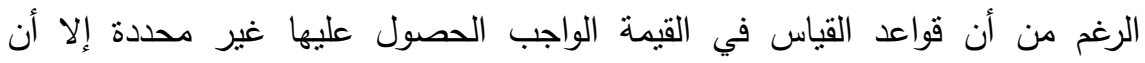

$$
\text { الحصول على ( • •، • ALPHA ) يعتبر مقبول. }
$$

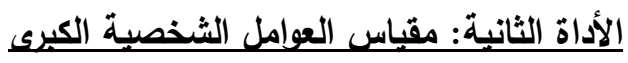

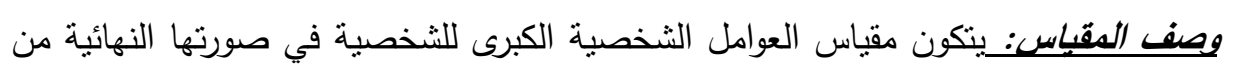
(rr) فقرة موزعة علي خمسة عوامل هي: الانبساطية وتتكون من ^ فقراتهو المقبولية

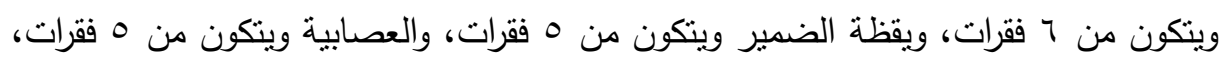

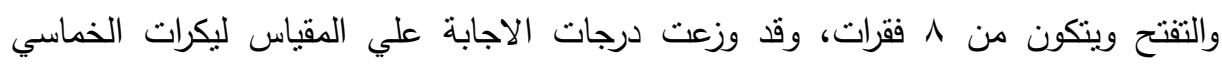
والجدول التالي يوضح التصحيح. أولا: تصحيح العبارات الايجابية

\begin{tabular}{|c|c|c|c|c|}
\hline موافق بشدة & موافق & غير متاكد & غير موافق & غير موافق بشدة \\
\hline 0 & $\varepsilon$ & $r$ & $r$ & 1 \\
\hline
\end{tabular}

تانياً: تصحيح العبارات السلبية

\begin{tabular}{|c|c|c|c|c|}
\hline موافق بشدة & موافق & غير متاكد & غير موافق & غير موافق بشدة \\
\hline 1 & $r$ & $r$ & $\varepsilon$ & 0 \\
\hline
\end{tabular}

أولا : صدق مقياس العوامل الخمسة الكبرى للشخصية: ا ـ معامل ارتباط درجة كل عبارة من عبارات المقياس كالتالي:

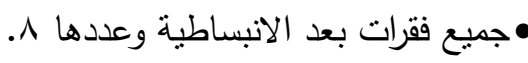
•وبعد المقبولية وعددها 7.

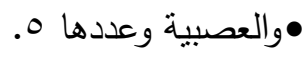
•والتفتح وعددها 1 و الفقرات حققت دلالة إحصائية عند مستوى معنوي (1 +.، . ).

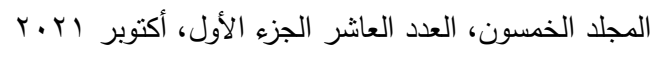

$$
\begin{aligned}
& \text { التزقيم الدولي 0826- ISSN 1110 } \\
& \text { الترقيم الدولي الموحد الإلكتروني 3178-2636-26 }
\end{aligned}
$$


r. الصدق البنائي: أوضحت النتائج أن جميع الابعاد ترنبط ببعضها البعض بالدرجة الكلية

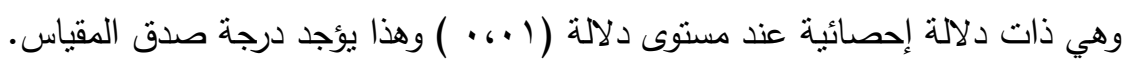
ثانيا: ثبات مقياسى العوامل الخمسة الكبرى للثخصية:

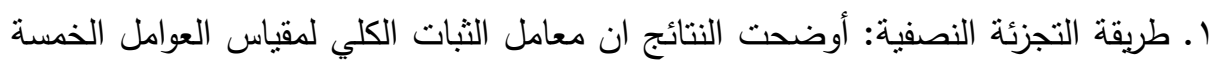
الكبرى للشخصية ( 11 \% \% ) وذلك دلالة على ان ابعاد القياس تتمتع بدرجة عالية من الثبات.

r. طريقة ألفاكرنباخ: أظهرت النتائج أن قيم ثيات أبعاد المقياس والتى تراوحت بين (r وج، •)

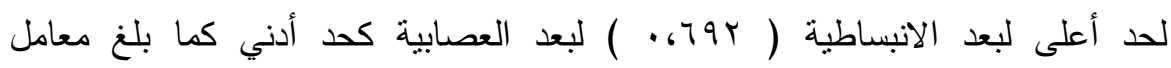

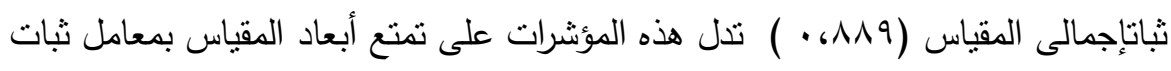
عال وبمقدرتها علي تحقيق اهداف الدراسة. المعالِاتِ الِْحصائية المستخدِمة فِي الآراسة: فيما يلي مجموعة من الأساليب الإحصائية المستخدمة في تحليل البيانات:

2 - نم حساب التكرارات والنسبة المئوية للتعرف على مفردات عينة الدراسة، وتحديد استجابات أفرادها تجاه عبارات أبعاد الدراسة.

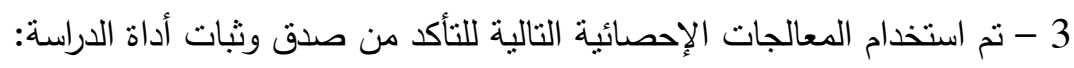

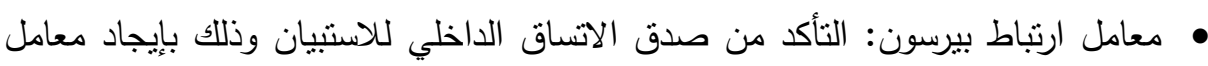

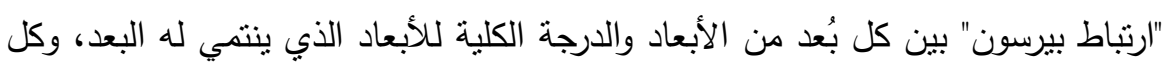
عبارة من العبارات مع البعد الذي تتنمي إليه العبارة.

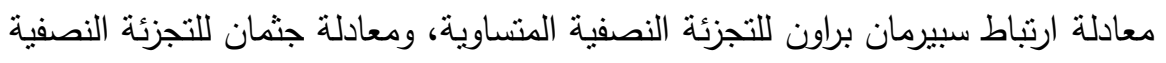
غير المتساوية، ومعامل ألفا كرونباخ: للتأكد من ثبات أداة الدراسة.

$$
\begin{aligned}
& \text { المجلد الخمسون، العدد العاثر الجزء الأول، أكتوبر ابr.r. }
\end{aligned}
$$

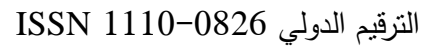

$$
\begin{aligned}
& \text { الترقيم الدولي الموحد الإلكتروني 3178-2636-26 }
\end{aligned}
$$


4 - المتوسط الحسابي Mean وذلك لمعرفة مدي ارتفاع أو انخفاض استجابات أفراد الدراسة عن كل عبارة من عبارات متغيرات الدراسة الأساسية.

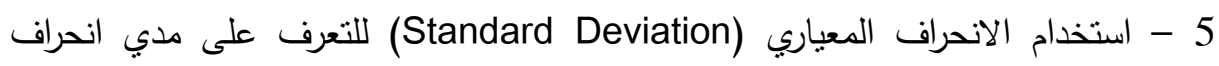
استجابات أفراد الدراسة لكل عبارة من عبارات متغيرات الدراسة ولكل بُعد من أبعادها

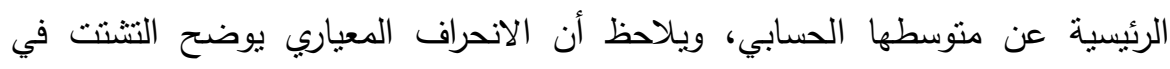
استجابات أفراد الدراسة لكل عبارة من عبارات منغيرات الدراسة إلى جانب أبعاد الدراسة، فكلما اقتربت قيمته من الصفر كلما تركزت الاستجابات وانخفض نتشتنها. 6 - تم استخدام المعالجات الإحصائية التالية لتحليل نتائج الدراسة الميدانية. • المتوسطات الحسابية والانحرافات المعيارية والمتوسط المئوي المرجح في نتائج التحليل الوصفي للمتغيرات. • اختبار t لكتوسط عينة واحدة (One sample T test). • • تم استخدام (Independent Samples T-test) للعينتين المستقلتين. نتائِج إختبار الفروض: الفرض الأول: نوجد فروق ذات دلالة إحصائية عند مسنوى دلالة (0.05 = م) في أبعاد ميكانزمات المواجهة والتكيف بين يمنيون خارج اليمن وسكان اليمن. وللتحقق من صحة هذا الفرض تم استخدام اختبار "ت" لعينتين مستقلتين.

$$
\begin{aligned}
& \text { المجلد الخمسون، العدد العاثر الجزء الأول، أكتوبر ابr.r. } \\
& \text { التزقيم الدولي 0826- ISSN 1110 } \\
& \text { الترقيم الدولي الموحد الإلكتروني 3178-2636-26 التربي }
\end{aligned}
$$


مجلة العلوم البيئية - مالية

كلية الدراسات العليا والبحوث البيئية - جامعة عين شس البئ

رغد زين العابدين محمد يوسف وآخرون

جدول رقم (ץ): يوضح المتوسطات والانحرافات المعيارية وقيمة "ت" ومستوى الدلالة للتعرف إلى الفروق في بين منوسطات درجات يمنيون خارج اليمن وسكان اليمن

\begin{tabular}{|c|c|c|c|c|c|c|c|}
\hline \multirow{2}{*}{ الفروق } & \multirow{2}{*}{ دلالة" دستوي } & \multirow{2}{*}{ قيمة t } & \multicolumn{2}{|c|}{ سكان اليمن ن = } & \multicolumn{2}{|c|}{ 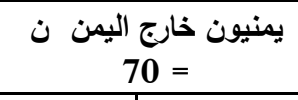 } & \multirow{2}{*}{ الميكانزمات } \\
\hline & & & $\varepsilon$ & م & $\varepsilon$ & P & \\
\hline لمارئ & $\begin{array}{c}0.00 \\
0\end{array}$ & $\begin{array}{c}5.84 \\
0\end{array}$ & $\begin{array}{c}4.72 \\
4\end{array}$ & $\begin{array}{c}22.0 \\
6\end{array}$ & $\begin{array}{c}3.85 \\
8\end{array}$ & 26.31 & المشكلات \\
\hline ليمالح & $\begin{array}{c}0.00 \\
0\end{array}$ & $\begin{array}{c}5.22 \\
9\end{array}$ & $\begin{array}{c}5.28 \\
7\end{array}$ & $\begin{array}{c}22.0 \\
7\end{array}$ & $\begin{array}{c}2.76 \\
4\end{array}$ & 25.80 & الانفعاليس \\
\hline لمارئ & $\begin{array}{c}0.00 \\
0\end{array}$ & $\begin{array}{c}3.72 \\
5\end{array}$ & $\begin{array}{c}3.40 \\
9\end{array}$ & $\begin{array}{c}24.0 \\
6\end{array}$ & $\begin{array}{c}3.88 \\
2\end{array}$ & 26.36 & الاجتماعية \\
\hline لمين & $\begin{array}{l}0 \\
0.034\end{array}$ & 2.136 & 6 & ${ }^{1} 6.10$ & 3 & $\begin{array}{r}18.0 \\
0\end{array}$ & التجنياتية \\
\hline
\end{tabular}

أولا: حل المشكلات: لقد أظهرت النتائج وجود فروق بين يمنيون خارج اليمن وسكان اليمن في بُعد حل المشكلات حيث كان منوسط حي يمنيون خارج اليمن (26.31) ومتوسط اليمن 146

$$
\begin{aligned}
& \text { المجلد الخمسون، العدد العاشر الجزء الأول، أكتوبر اب.r.T } \\
& \text { التزقيم الدولي 0826- ISSN 1110 } \\
& \text { التزقيم الدولي الموحد الإلكتروني 3178-2636 }
\end{aligned}
$$


(25.48)، وقيمة "ت" (5.840) عند مستوي معنوية (0.05)، وهي بذلك تكون دالة

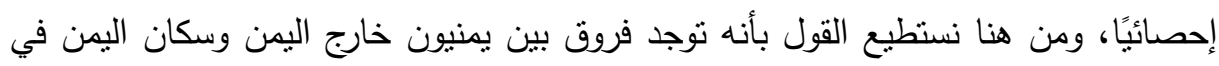

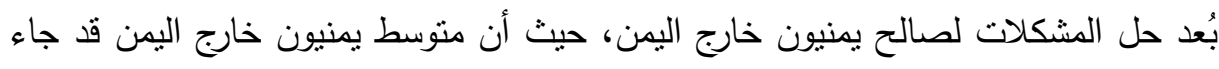
أكبر من متوسط سكان اليمن.

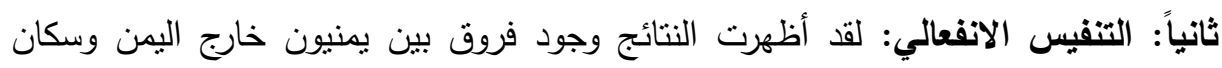

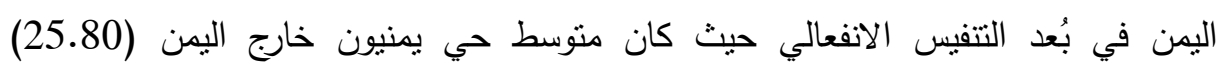

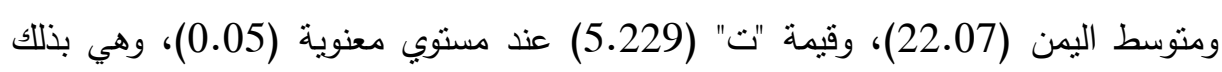

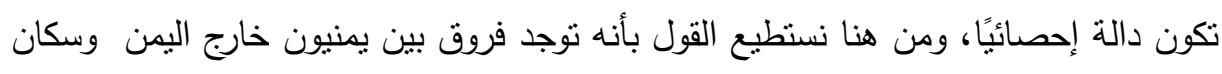

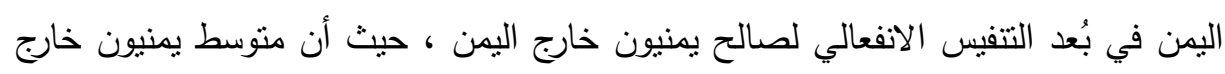
اليمن قد جاء أكبر من متوسط سكان اليمن.

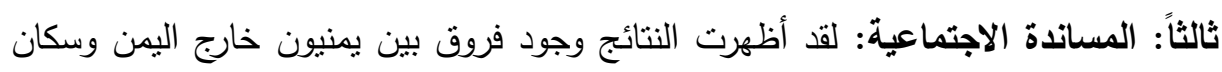

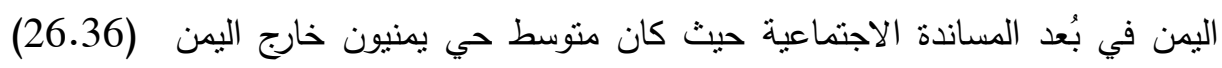

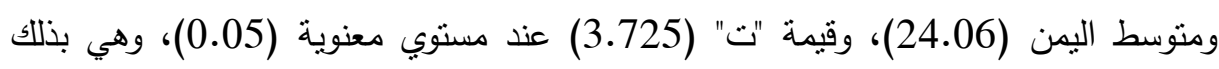

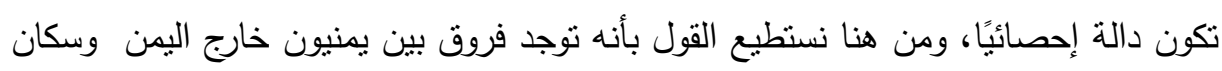

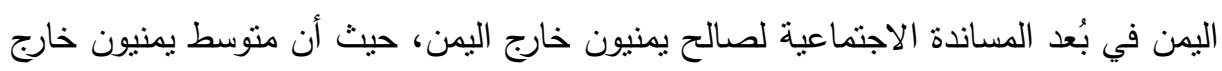
اليمن قد جاء أكبر من متوسط سكان اليمن.

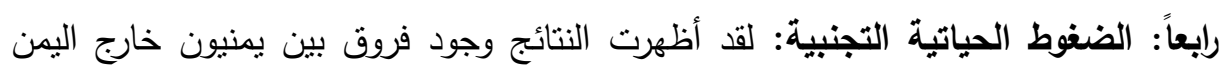

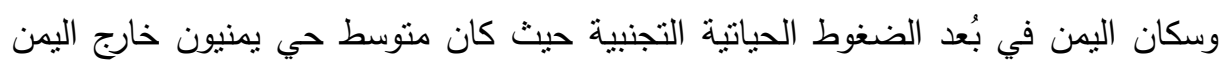

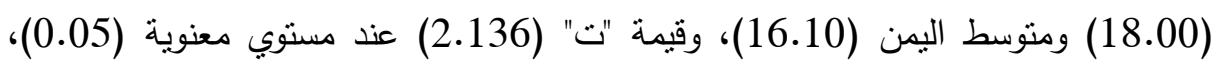

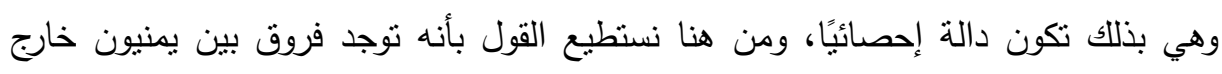

$$
\begin{aligned}
& \text { المجلد الخمسون، العدد العاثر الجزء الأول، أكتوبر ابr.r. }
\end{aligned}
$$

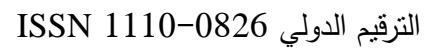

$$
\begin{aligned}
& \text { الترقيم الدولي الموحد الإكتروني 3178-2636 }
\end{aligned}
$$


اليمن وسكان اليمن في بُعد الضغوط الحياتية التجنبية لصالح يمنيون خارج اليمن، حيث أن متوسط يمنيون خارج اليمن قد جاء أكبر من منوسط سكان اليمن.

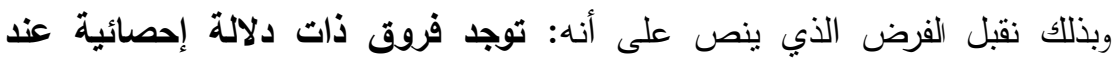

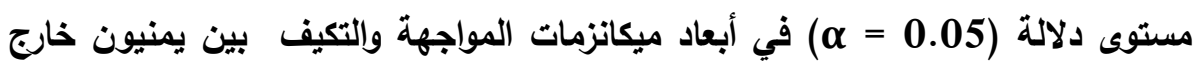

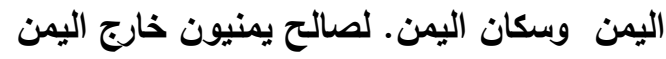
تفسير نتائج الفرض الاول: أظهرت النتائج العامة الدراسات وجود فروق ذات دات دالة احصائيا

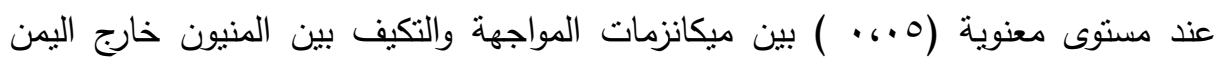
وسكان اليمن لصالح يمنيون خارج اليمن وذللك تتفق مع الدراسات السابقة الني نتاولت ابعاد وميكانيزمات المواجهة والتكيف. لهن لهن

إلا أن هذه النتيجة اختلفت مع بعض الدراسات السابقة للاخضري والتي تتشير الى ان

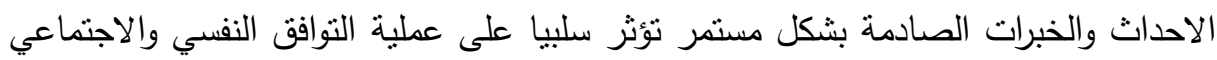
مما يؤدي الى حدوث صدمات نفسية واضطرابات سلوكية وانفعالات عقلية. الفرض الثاني: توجد فروق ذات دلالة إحصائية عند مستوى دلالة (205 ميكاتزمات المواجهة والتكيف بين الأكور والإناث. وللتحقق من صحة هذا الفرض تم استخدام اختبار "ت" لعينتين مستقلتين. 
مجلة العلوم البيئية

كلية الدراسات العليا والبحوث البيئية - جامعة عين شمس الئل

رغد زين العابدين محمد يوسف وآخرون

جدول رقم (ץ): يوضح المتوسطات والانحرافات المعيارية وقيمة "ت" ومستوى الدلالة للتعرف

إلى الفروق في بين متوسطات درجات الذكور والاناث

\begin{tabular}{|c|c|c|c|c|c|c|c|}
\hline \multirow[b]{2}{*}{ الفروق } & \multirow{2}{*}{ دلالةّي } & \multirow[b]{2}{*}{ قيمة t } & \multicolumn{2}{|c|}{ إناث ن = } & \multicolumn{2}{|c|}{ ذكور ن = 78} & \multirow{2}{*}{ الميكانزمات } \\
\hline & & & $\varepsilon$ & e & $\varepsilon$ & r & \\
\hline فنوجد & 0.427 & 0.797 & 4.568 & 23.82 & 4.985 & 24.47 & المشكلات \\
\hline فترون & 0.883 & 0.148 & 4.833 & 23.87 & 4.439 & 23.99 & الانفعاليس \\
\hline 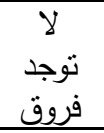 & 0.251 & 1.153 & 4.053 & 24.79 & 3.613 & 25.54 & الاجتماعية \\
\hline 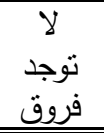 & 0.467 & 0.730 & 5.658 & 17.42 & 5.069 & 16.76 & التينيتية \\
\hline
\end{tabular}

لقد أظهرت نتائج الجدول السابق أن عدم وجود فروق ذات دلالة إحصائية بين الذكور

والاناث في أبعاد مقياس ميكانزمات المواجهة والتكيف ، وبالتالي عدم تحقق الفرض القائل

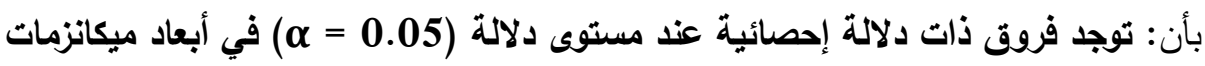

المواجهة والتكيف بين الأكور والإناث.

تفسير نتائج الفرض الثاني: نوجد فروق ذات دلالة احصائية في ابعاد ميكانزمات المواجهة

$$
\text { والتكيف بين الذكور والاناث: }
$$

أظهرت النتائج الدراسية عدم وجود فروق ذات دات دلالة احصائية عند مستوى معنوية(ه •، •) بين الذكور والاناث. فى ابعاد مقياس مكنزمات المواجهة والتكيف بين الذكور

$$
\begin{aligned}
& \text { المجلد الخمسون، العدد العاثر الجزء الأول، أكتوبر اب.r.T }
\end{aligned}
$$

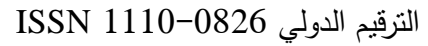

$$
\begin{aligned}
& \text { الترقيم الدولي الموحد الإلكتروني 3178-2636 }
\end{aligned}
$$


والاناث وبالتالي عدم تحقق الفرد القائل بانه نوجد فروق ذات دلالة احصائية عند مستوى معنوية (0 •، •) في أبعاد ميكانزمات المواجهة والتكيف بين الذكور والاناث. واتفقت هذه النتيجة مع الدراسات السابقة لأن وقع الخبرات الصادمة علي جميع افراد التراد

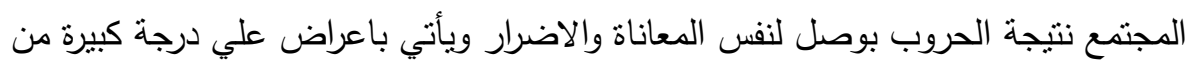
التقارب بين الجنسين. الفرض الثالث: توجد فروق ذات دلالة إحصائية عند مستوى دلالة (0.05 = م) في العوامل الخمسة الكبرى للشخصية بين يمنيون خارج اليمن وسكان اليمن. وللتحقق من صحة هذا الفرض نم استخدام اختبار "ت" لعينتين مستقلتين.

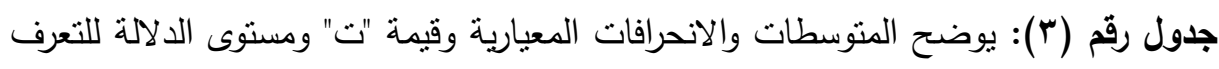

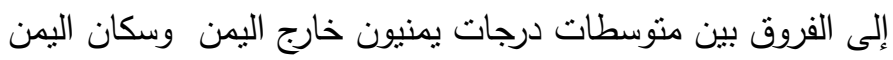

\begin{tabular}{|c|c|c|c|c|c|c|c|}
\hline \multirow{2}{*}{ القزاه } & \multirow{2}{*}{ مستلة بَ } & \multirow[t]{2}{*}{ قيمة t } & \multicolumn{2}{|c|}{ سكان اليمن ن } & \multicolumn{2}{|c|}{ اليمن نيون = النيج } & \multirow[t]{2}{*}{ أبعاد المقياس } \\
\hline & & & $\varepsilon$ & 5 & $\varepsilon$ & 8 & \\
\hline فروق توجد & 0.753 & 0.315 & 5.072 & 33.31 & 5.650 & 33.60 & الانبساطية \\
\hline لا نوجد & 0.665 & 0.434 & 4.163 & 25.13 & 4.024 & 25.43 & المقبولية \\
\hline لا نا توجد & 0.066 & 1.854 & 3.073 & 20.21 & 3.478 & 21.24 & يقظة الضمير \\
\hline لصالح اليمن & 0.000 & 3.712 & 2.881 & 21.86 & 3.426 & 19.87 & العصابية \\
\hline لصالح اليمن & 0.001 & 3.261 & 5.161 & 33.13 & 4.399 & 30.49 & التقتح \\
\hline
\end{tabular}

من ملاحظة الجدول السابق نجد أن الفرض قد نحقق بشكل جزئي، حيث كانت هناك

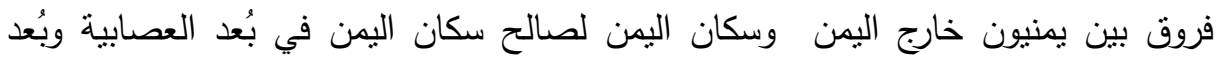
التقتح، في حين لم تكن هناك فروق بين يمنيون خارج اليمن وسكان اليمن في باقي أبعاد 


\section{تفسير نتائج الفرض الثالث:}

توجد فروق ذات دلالة احصائية في العوامل الخمسة الكبرى للثخصية بين اليمنيون

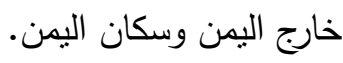

أظهرت الدراسة وجود فروق ذات دلالة احصائية عند مستوى معنوية( هـ، .) في

العوامل الخمسة الكبرى للشخصية بين اليمنيون خارج اليمن وسكان اليمن.

كما اظهرت الدراسات ان هذا الغرض قد تتحقق بشكل جزئي حيث كانت هناك فروق

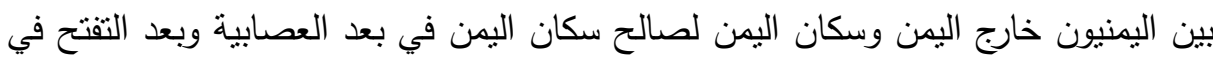
حين لم تكن هناك فروق بين يمنيون خارج اليمن وسكان اليمن في باقي ابعاد مقياس العوامل لئل الخمسة الكبرى للشخصية.

الفرض الرابع: توجد فروق ذات دلالة إحصائية عند مستوى دلالة (ل05 =0.05) في العوامل الخمسة الكبرى للشخصية بين الذكور والاناث.

وللتحقق من صحة هذا الفرض نم استخدام اختبار "ت" لعينتين مستقلنين.

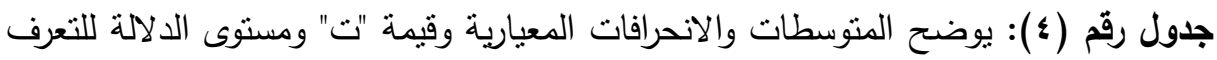
إلى الفروق بين متوسطات درجات الذكور والاناث

\begin{tabular}{|c|c|c|c|c|c|c|c|}
\hline \multirow{2}{*}{ الفروق } & \multirow{2}{*}{ دلالة بَّي } & \multirow[t]{2}{*}{ قيمة t t } & \multicolumn{2}{|c|}{ إناث ن = 62} & \multicolumn{2}{|c|}{ ذكور ن = 78} & \multirow[t]{2}{*}{ أبعاد المقياس } \\
\hline & & & $\varepsilon$ & ? & $\varepsilon$ & $\rho$ & \\
\hline لالانالح & 0.000 & 3.930 & 3.581 & 35.35 & 6.028 & 31.95 & الاتبساطية \\
\hline لا توجد & 0.082 & 1.752 & 3.873 & 25.95 & 4.189 & 24.74 & المقبولية \\
\hline لالانوجد & 0.335 & 0.967 & 3.263 & 21.03 & 3.349 & 20.49 & يقظة الضمير \\
\hline لالنوجد & 0.775 & 0.286 & 3.154 & 20.77 & 3.443 & 20.94 & العصابية \\
\hline لالون & 0.443 & 0.787 & 4.661 & 32.18 & 5.194 & 31.51 & التقتح \\
\hline
\end{tabular}

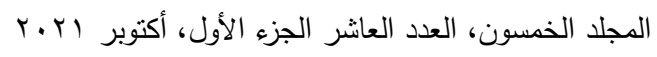

التزقيم الدولي 0826-0 1110 110

الترقيم الدولي الموحد الإلكتروني 3178-2636 
من ملاحظة الجدول السابق نجد أن الفرض قد تحقق بشكل جزئي، حيث كانت هناك

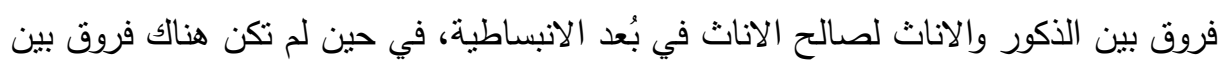
الذكور والاناث في باقي أبعاد مقياس في العوامل الخمسة الكبرى للشخصية.

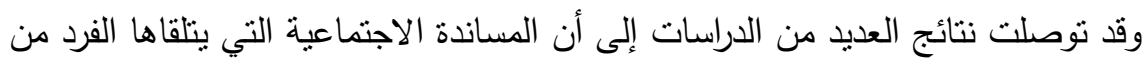
الآخرين سواء في الأسرة أو خارجها، تعد عاملا هاما في صحته النفسية، ومن ثم يمكن التتبؤ

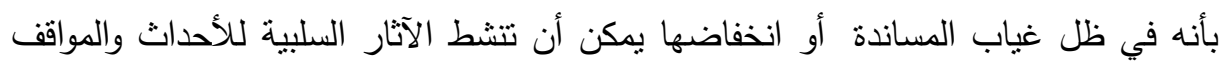

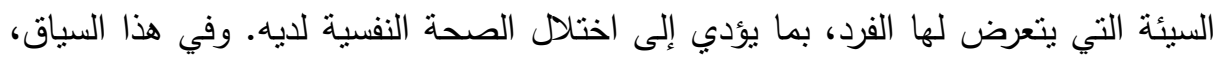
يذهب Coyne وآخرون (1991) نقلا عن عثمان يخلف (2001) إلى أن المساندة الاجنماعية يمكن أن تخفض أو تستبعد عواقب أحداث الحياة على الصحة.

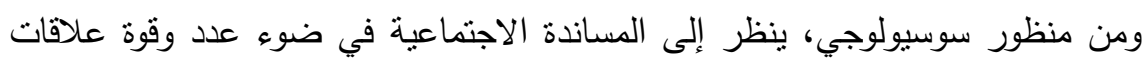

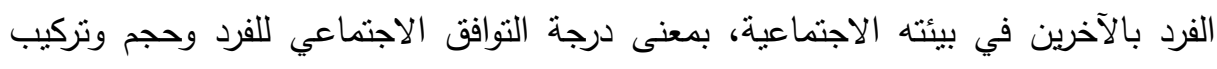

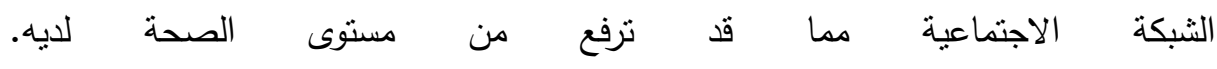
ويضيف Cutrona و Russell (1990) نقلا عن عثمان يخلف (2001) إلى أن المساندة

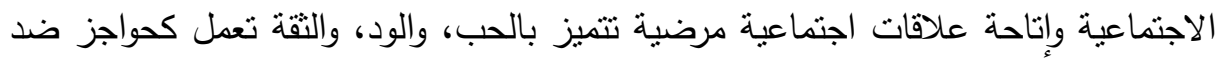
التأثنر السلبي لأحداث الحياة على الصحة الجسمية والنفسية.

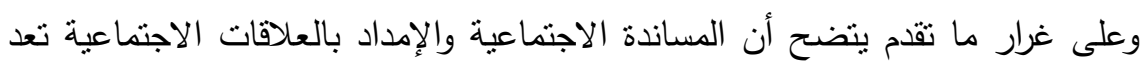

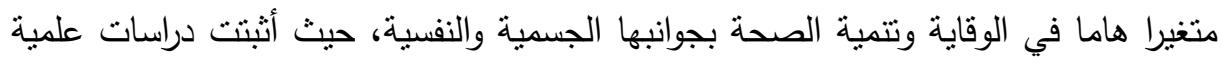
وطبية وبيئية حديثة الفوائد الصحية للمساندة الاجتماعية على صحة وسلامة العقل والجسم.

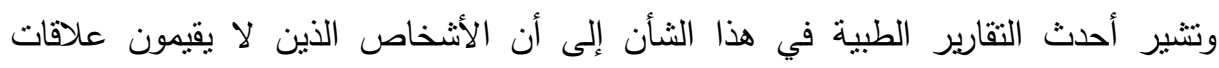

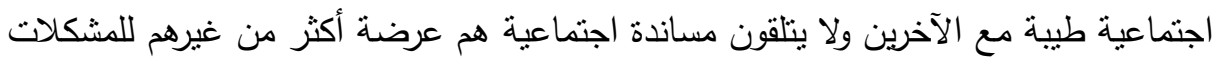
الصحية، حيث يظهر دور الروابط الاجتماعية والمساندة العاطفية في الحفاظ على الصحة الصنة

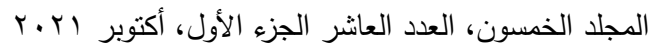

$$
\begin{aligned}
& \text { التزقيم الدولي 0826- ISSN 1110 } \\
& \text { الترقيم الدولي الموحد الإلكتروني 3178-2636-26 التروب }
\end{aligned}
$$


والوقاية من المرض. وتفسير ذلك حسب "Cobb أن الروابط الاجتماعية والمساندة العاطفية تعمل على تعميق التوافق النفسي والاجتماعي للأفراد وتتمي روح الانتماء لديهر، حيث يشعرون بأنهم جزء من شبكة اجتماعية قوية ومتماسكة يمكن أن توفر لهم الحماية

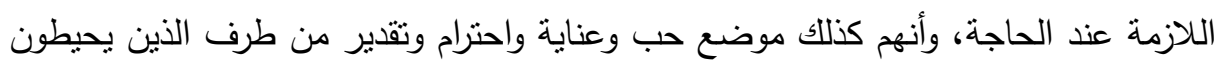

وفي السياق نفسه، أثنار كل من Brownwell و Shumaker (1984) إلى أن وظائف المساندة الاجتماعية تختلف حسب نوعيتها ومكانتها عند المتلقي أي كيفية إدراكها ، لهذا يقسمها إلى قسمين رئيسين هما: وظائف مساندة الحفاظ على الصحة الجسمية والنفسية والعقلية ووظائف تخفيف أو الوقاية من الآثار النفسية السلبية لأحداث الحياة الضاغطة.

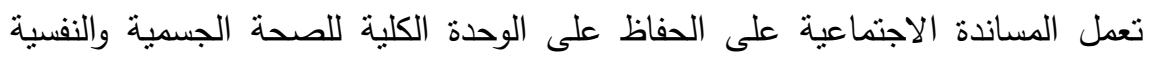
والعقلية للوصول إلى تعزيز ودعم إحساس المتلقي بالراحة النفسية والاطمئنان في حياته والثعور بالسعادة، وذللك من خلال إثباع حاجات الانتماء، فالمساندة تتمي أنماط التماعلى التفاعل

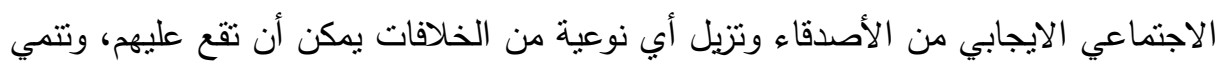

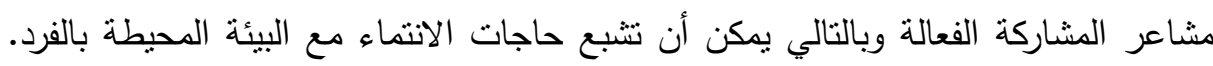

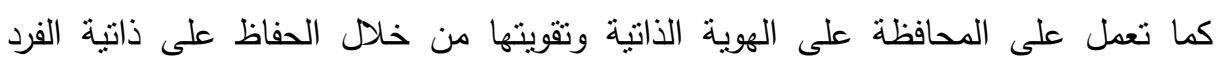
وإحساسه بهويته الذاتية في إطار دعم العلاقات الثخصية بالمحيطين به ومن خلال تتمية لإنها مصادر التغذية الرجعية المرتبطة بمظاهر الذات للوصول إلى اتفاق دعي في الآراء ووجهات النظر • كما تعمل أيضا على تقوية مفهوم احترام الذات من خلال تعزيز مفهوم احترام الذات لاى الفرد داخل الجماعة التي ينتمي إليها، وتتمي إحساسه بالكفاءة الثخصية.

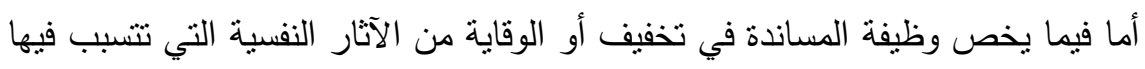

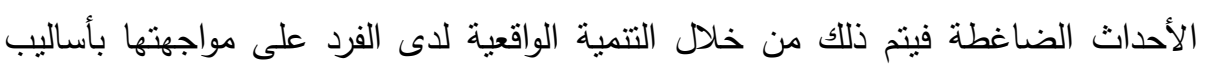

$$
\begin{aligned}
& \text { المجلد الخمسون، العدد العاثر الجزء الأول، أكتوبر ابr.r. }
\end{aligned}
$$

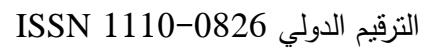

$$
\begin{aligned}
& \text { الترقيم الدولي الموحد الإكتروني 3178-2636 }
\end{aligned}
$$


ايجابية. حيث يقوم الفرد بتفسير عوامل الأحداث الضاغطة وتتدخل المساندة الاجتماعية في تعميق هذا التفسير بو تحسن مهمته بصورة ايجابية حتى يستطيع أن يواجهها بتفاعلات

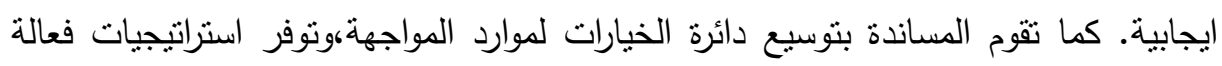
لمواجهة نموذجية انفعالية وسلوكية وتقوم أيضا بتوفير المعلومات اللازمة لهذه المواجهة والأساليب المختلفة لحل المشكلات التي يعبر عنها. من خلال ما سبق نرى أن وظائف المساندة تختلف حسب المواقف الحياتية للفرد سواء كانت ضاغطة أو لا، وهي تعمل على المشاركة الفعالة مع الآخرين، وتتشكيل شبكات العلاقات والاتصالات النوعية التي نساهم في تخفيف الضغوط والوقاية من الآثار السلبية لأحداث الحياة وكذلك للحفاظ على الصحة الجسمية والنفسية والعقلية.

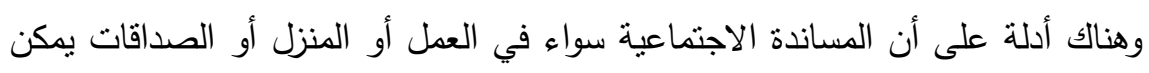
أن تزودنا بعازل فعال ومخفف للصدمات ضد آثار الضغوط النفسية وتساهم في التوافق النفسي الاجتماعي الفعال في البيئة المحيطة بالفرد. (هارون نوفيق الرشيدي، 1999 1999) .ومن جهته يؤكد كل من أحرشاو والزاهر (2001) أن البطالة حدث حياتي ضاغط الهائة له اله انعكاس سلبي مباشر على الحياة النفسية والاجتماعية للشخص، ويرجع ذلكاولك أساسا إلى أهمية ومكانة

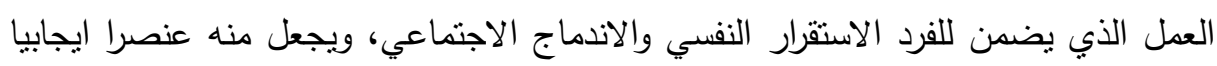

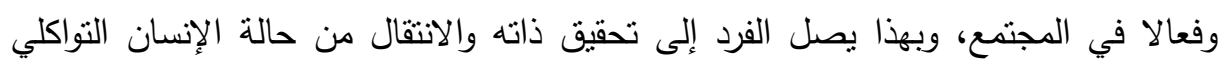

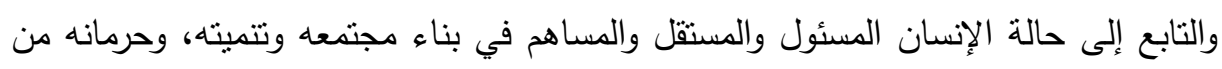

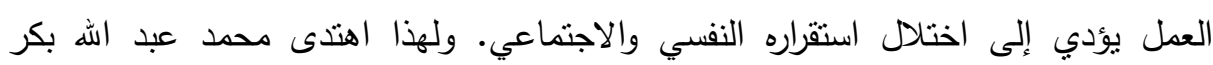
(2004) إلى أن أهمية العمل تكمن في تحقيق الاكتفاء المادي والمكانة الاجتماعية، فهو

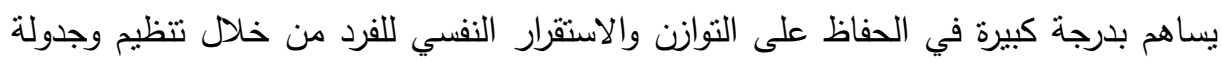
وقته واستغلاله في تحقيق أهداف ومقاصد عامة وممارسة أنشطة تجنب الفرد التأثير السلبي

$$
\begin{aligned}
& \text { المجلد الخمسون، العدد العاثر الجزء الأول، أكتوبر ابr.r. } \\
& \text { التزقيم الدولي 0826- ISSN 1110 } \\
& \text { الترقيم الدولي الموحد الإكتروني 3178-2636 }
\end{aligned}
$$


لوقت الفراغ الذي يخلق حالة من اللامبالاة عند الفرد ويعمق من شعوره بعدم جدوى وجوده

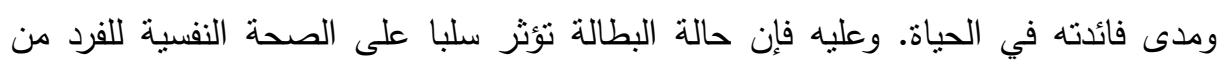
خلال عنصر الفراغ وعدم الفعالية مما يؤدي إلى ظهور مختلف مظاهر سوء النوافق النفسي والاجتماعي للفرد.

إن عدم التوافق النفسي والاضطرابات الثخصبة التي يتعرض لها الفرد نتيجة البطالة قد لا يقتصر تأثيرها السلبي على الفرد ، بل كثيرا ما تؤثر على أسرته أيضا. وتبرز المشكلة

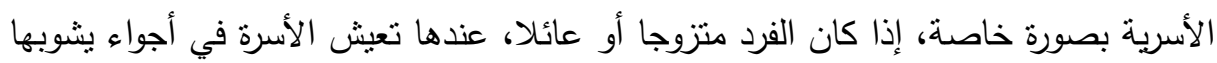
فترات من التوترات النفسية وسوء التوافق النفسي والاجتماعي، وقد ينجر عن ذلك غياب التكافل والمساندة الاجتماعية والأسرية. وفي هذا الصدد، يرى الزواوي خالد محمد (2004) أن العلاقات الإنسانية الايجابية مع والاند المواطن اليمني عن العمل والوقوف بجانبه ومساندته من شأنها أن ترفع من معنوياته وتعزيز

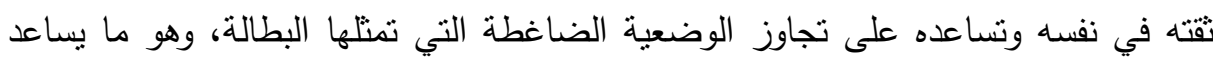
على تفادي الكثير من الانعكاسات السلبية للبطالة على الصحة النفسية والحياة الاجنماعية للعاطل.

\section{همبروايت الدراسمة}

تقترح الباحثة ما يلي:

1-إجراء دراسة للتعرف على أنز الحروب نفسيا واجتماعيا واقتصاديا لمواجهتها أو التخفيف

$$
\text { منها. }
$$

r- التركيز على الخبرات الصادمة خاصة لدي الالطفال ، المرأة ، المسنين والثباب ومعالجتها.

$$
\begin{aligned}
& \text { المجلد الخمسون، العدد العاثر الجزء الأول، أكتوبر ابr.r. }
\end{aligned}
$$

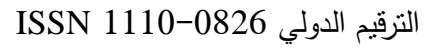

$$
\begin{aligned}
& \text { الترقيم الدولي الموحد الإلكتروني 3178-2636-26 }
\end{aligned}
$$


r-إجراء دراسة حول الصلابة النفسية وعلاقتها بالتوافق النفسي والاجتماعى لدى أفراد

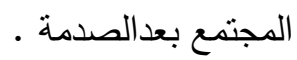

ع - إجراء دراسة الخبرات الصادمة وعلاقتها بالصلابة النفسية لاى المرأة لطبيعتها الخاصة. 0- عمل برامج إرشادية للتخفيف من إضطراب ما بعد الصدمة.

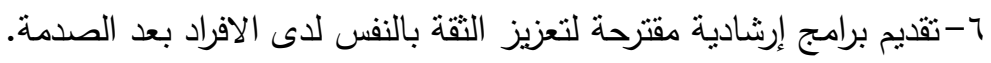

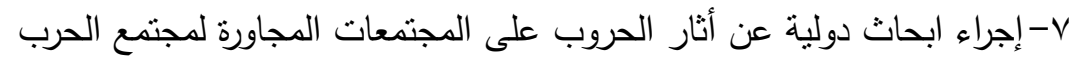

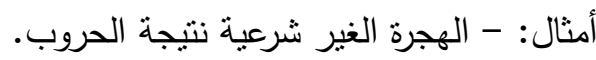
- انتشار الاوبئة. - ما تتحمله المنظمات الدولية الانسانية نتيجة الحروب.

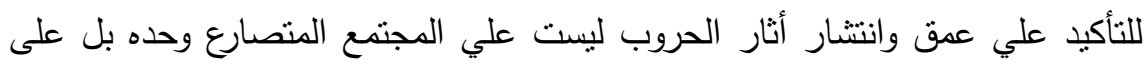

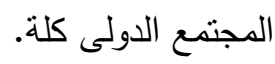

\section{entl}

ابراهيم العبدالستار (£99 19 ) العلاج النفسي السلوكي المعرفي الحديث: اساليبه وميادين نطبيقه، دار الفجر لنشر والتوذيع.

أثر الحرب علي الصحة النفسية في اليمن: أزمة مهملة | مركز صنعاء للاراسات الاستراتيجية

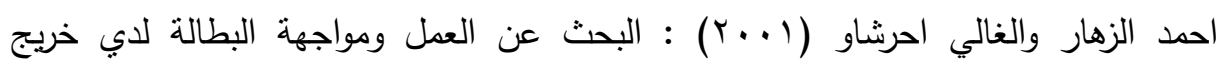

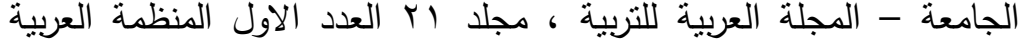

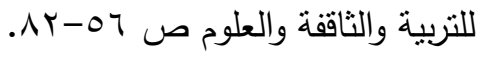

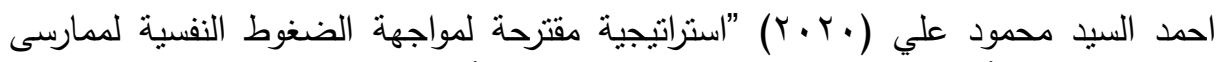

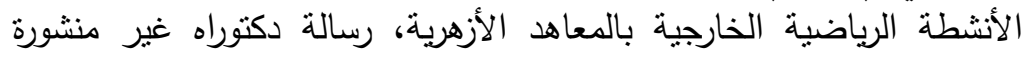

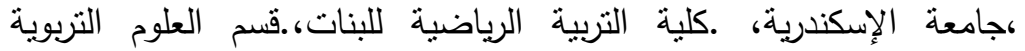

$$
\text { والنفسية والاجتماعية. }
$$

156

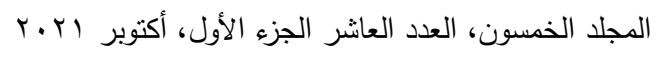

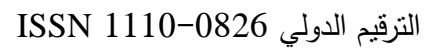

$$
\begin{aligned}
& \text { الترقيم الدولي الموحد الإلكتروني 3178-2636-26 }
\end{aligned}
$$


اشرف محمد عبد الغني الثربيني ز محمد السيد حلاوة (r . . r) الصحة النفسية بين النظرية والتطبيق المكتب الجامعي الحديث - الازاريطة - الاسكندرية.

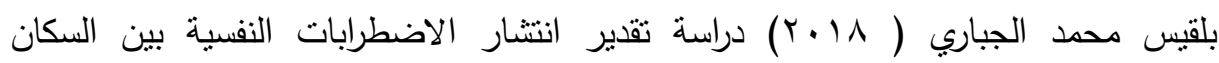

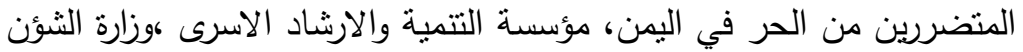
الاجتماعية والعمل ،صنعاء، جمهورية اليمن.

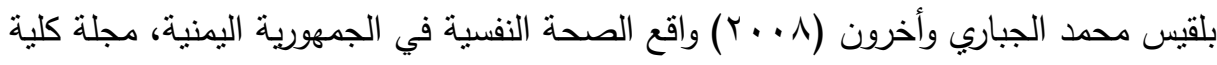

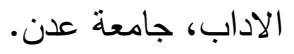

خالد محمد الزواوي (ع . . ؟): البطالة في الوطن العربي ( المشكلة والحل ) - مجموعة النبل العربي للطباعة والنشر . النط

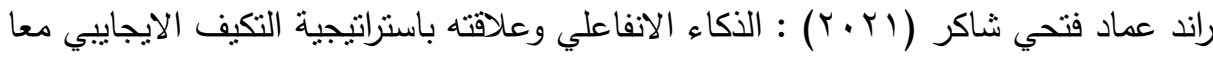

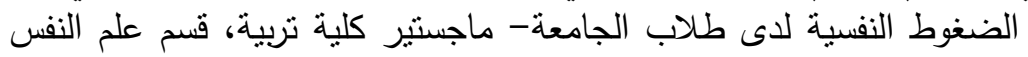

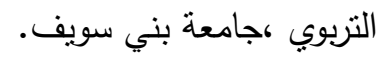

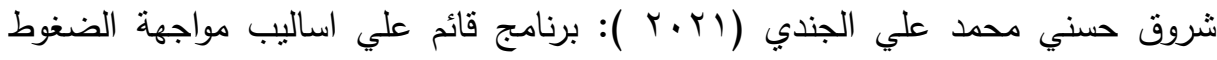

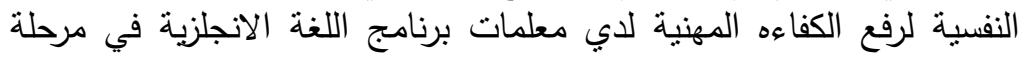

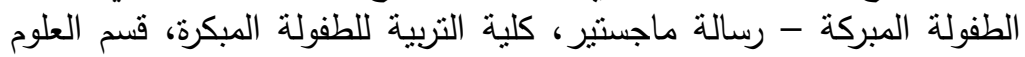

$$
\text { النفسية، جامعة بنى سويف }
$$

صالح الدهري وناظم العبيدي (999 199) الثخصية والصحة النفسية، دار الكندي للنشر الطبعة

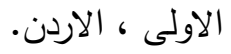

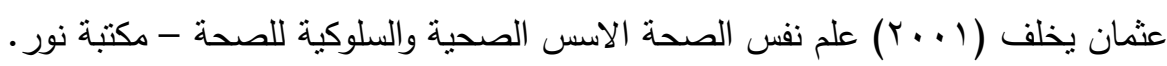

فرج عبدالقادر طه (999 (199) اصول علم النفس الحديث - عيد الدراسه والبحوث الانسانية والاجتماعية - مجمع اللغة العربية.

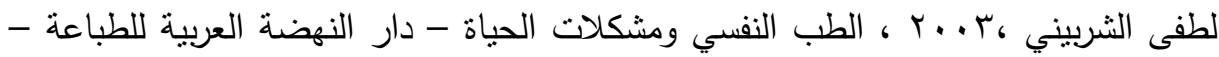

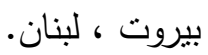

$$
\begin{aligned}
& \text { المجلد الخمسون، العدد العاثر الجزء الأول، أكتوبر ابr.r. } \\
& \text { التزقيم الدولي 0826- ISSN 1110 } \\
& \text { الترقيم الدولي الموحد الإلكتروني 3178-2636-26 }
\end{aligned}
$$




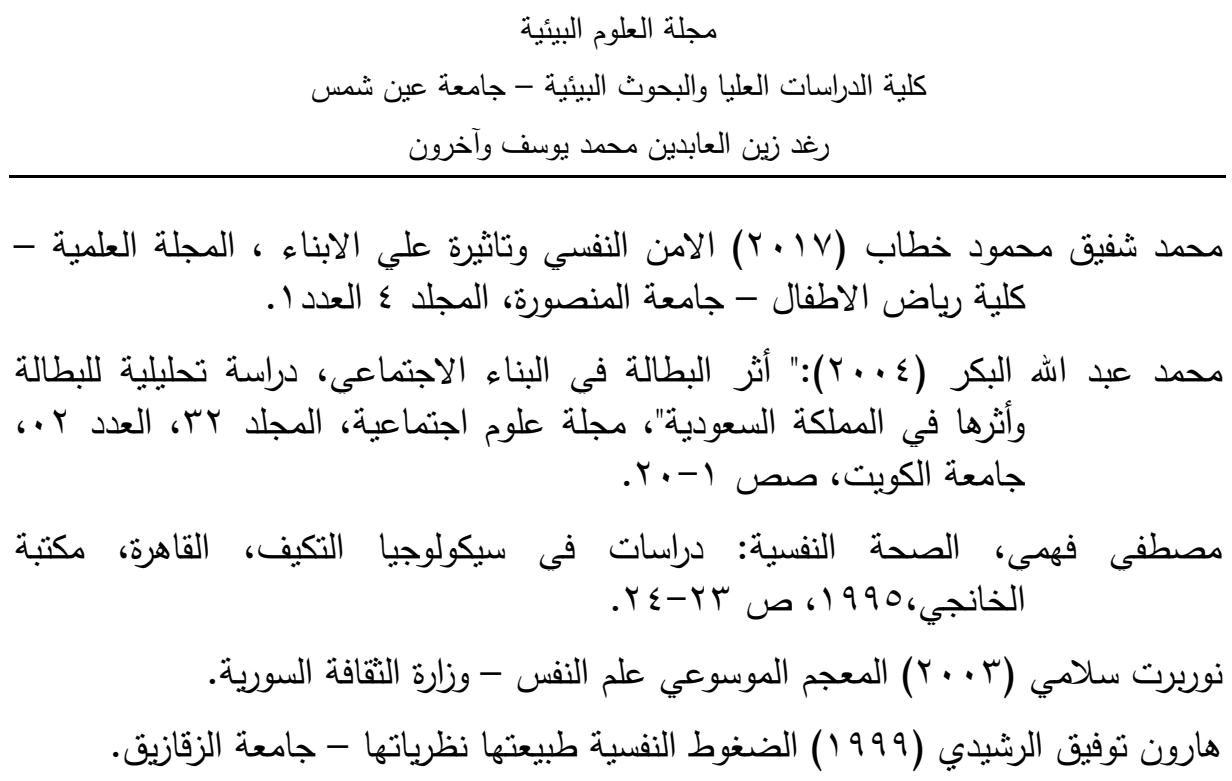

Brisbane, association sociological international, family to the bane or boon, migration, Vinita (2002) ISA, Australia.

Christian, J. \& Krageloh, A.)2012(: How Religious coping is used relative to other coping strategies depends on the individual level of religiosity and spirituality, Journal Of Religion \& Health, Dec., vol.51, issue 4, p 176-182

Cutrona, C. E., \& Russell, D. W. (1990). Type of social support and specific stress: Toward a theory of optimal matching. In B. R. Sara son, I. G. Sarason, \& G. R. Pierce (Eds.), Social support: An interactional view (pp. 319-366). New York: John Wiley \& sons.

Cobb, S. (1976). Social support as a moderator of life stress. Psychosomatic Medicine, 38(5), 300-314.

E. Kazlauskas, P. Želvienè, Relationship between stressor exposure, subjective health, sociodemographic factors and

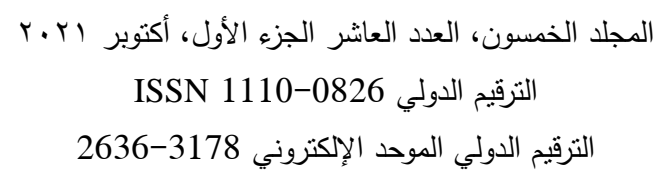




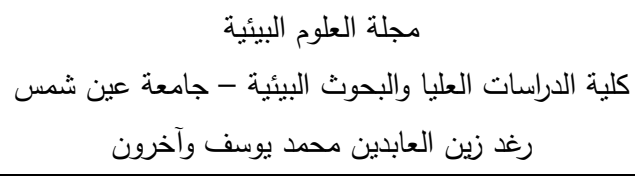

psychological well-being, Visuomenès sveikata 4 (2012), 96-103. (in Lithuanian)

Gillath, O. \& Hart, J. )2010(. The effects of psychological security and insecurity on political attitudes and leadership preferences. European Journal of Social Psychology, Vol. 40 )1(, p122134.

J. Cottraux, les thérapies comportementales et cognitives, masson, Paris, 1990 , p 204

Kadhiravan S., Kuma K., )2012(. Enhancing stress coping skills among college students, Researchers World : Journal Of Arts, Science \& Commerce, Oct, vol 4, issue1, p54-62.

Lazarus, R. S., \& Folkman, S. (1984). Stress, appraisal and coping. New York: Springer Publishing Company.

Londerville, S., \& Main, M. (1981). Security of attachment, compliance, and maternal training methods in the second year of life. Developmental Psychology, 17(3), 289-299.

Macneil, N. et al )2012(. The effects of avoidance coping and coping self -effcacy on eating disorder attitudes and behaviors, Eating Behaviors, vol.13, issue 4, p 143-149

Shumaker, S. A., \& Brownell, A. (1984). Toward a theory of social support: Closing conceptual gaps. Journal of Social Issues, 40(4), 11-36

Phile, J. \& Swanepoel, P. )2012(: The role of coping in the relationship between spiritual wellbeing and depression among ministers, Hervormde Teologiese Studies, vol., 68, issue 1, p 1-9.

$$
\begin{aligned}
& \text { المجلد الخمسون، العدد العاثر الجزء الأول، أكتوبر ابr.r } \\
& \text { التزقيم الدولي 0826- ISSN 1110 } \\
& \text { التزقيم الدولي الموحد الإكتروني 3178-2636 }
\end{aligned}
$$




$$
\begin{aligned}
& \text { مجلة العلوم البيئية } \\
& \text { كلية الدراسات العليا والبحوث البيئية - جامعة عين شمس الئس } \\
& \text { رغد زين العابدين محمد يوسف وآخرون }
\end{aligned}
$$

un security council,Letter dated 27 January 2017 from the Panel of Experts on Yemen addressed to the President of the Security Council (S/2017/81); human rights inyemen , including violations and abuses since september 2014, U.N. doc A/HRC/36/33. ( sep.5.2017)

\title{
THE COPING AND ADAPTTATION MECHANISMS OF THE YEMENI FAMILY IN THE LIGHT OF \\ CURRENT EVENTS
}

\author{
Raghd Z. M. Yousf ${ }^{(1)}$; Ahmed M. Alatiq ${ }^{(2)}$ \\ and Mostafa I. Awad ${ }^{(2)}$
}

1) Post Grad. Student, Faculty of Graduate Studies and Environmental Research, Ain Shams University 2) Department of Environmental Humanities Sciences, Faculty of Graduate Studies and Environmental Research, Ain Shams University

\begin{abstract}
The study aims to determine the mechanisms of confrontation and adaptation in the Yemeni family in light of the current events. The study relied on the theory of psychological adaptation, psychological adaptation, a continuous dynamic process, by which the individual aims to change his behavior, in order to create a more compatible and balanced relationship with the environment, as the researchers used the scale of the five major dimensions of personality. (Neuroticism, extroversion, dedication, the factor of gentleness, and the factor of openness to experience) and the questionnaire of the mechanisms of confrontation and adaptation in the Yemeni family in light of the current events and the sample participating in the study was conducted 160

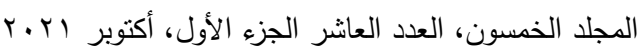

$$
\begin{aligned}
& \text { التزقيم الدولي 0826-1110 1SSN } \\
& \text { الترقيم الدولي الموحد الإلكتروني 3178-2636 }
\end{aligned}
$$




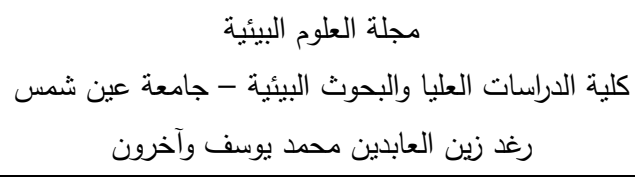

this study on a group of (140) Yemeni families as the researchers used the method Descriptive and analytical, and to analyze the results, the researchers used the following statistical methods: frequencies and percentages, the arithmetic mean, standard deviation, alphakronbach coefficient, half segmentation coefficient, Pearson correlation coefficient, (T) test, variance analysis test, gradual regression analysis test. The most important results of the study were the following: There are statistically significant differences at the level of significance $(\alpha=$ 0.05 ) in the dimensions of confrontation and adaptation mechanisms between Yemenis outside the right and the Yemeni population. There are statistically significant differences at the level of $(\alpha=0.05)$ in the dimensions of the coping and coping mechanisms between males and females. There are statistically significant differences at the level of ( $\alpha$ $=0.05)$ in the big five factors of personality between males and females. There are statistically significant differences at the level of significance $(\alpha=0.05)$ in the five major factors of personality between Yemenis outside the right and the population of Yemen. The researchers recommend social support as an important source of effective psychosocial support that a person needs, as the size of the support and the level of satisfaction with it affect how an individual perceives life events, methods of dealing with them, and their repercussions on his health.

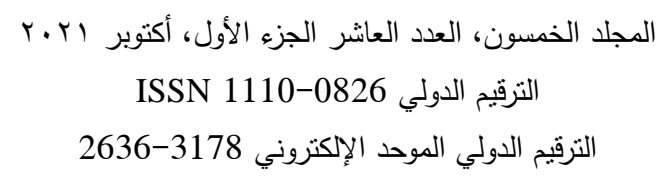

